OPEN ACCESS

Edited by:

Wei Zhao,

Chengdu Medical College, China

Reviewed by:

Longxiang Xie,

Henan University, China

Yunlong Lei,

Chongqing Medical University, China

*Correspondence:

Jie Lin

linjieshi@126.com

NaXie

naxie@scu.edu.cn

${ }^{\dagger}$ These authors have contributed equally to this work

Specialty section:

This article was submitted to Molecular and Cellular Oncology, a section of the journal

Frontiers in Cell and Developmental

Biology

Received: 14 December 2020

Accepted: 05 February 2021

Published: 01 March 2021

Citation:

Wu P, Gao W, Su M, Nice EC,

Zhang W, Lin J and Xie N (2021)

Adaptive Mechanisms of Tumor

Therapy Resistance Driven by Tumor

Microenvironment.

Front. Cell Dev. Biol. 9:641469.

doi: 10.3389/fcell.2021.641469

\section{Adaptive Mechanisms of Tumor Therapy Resistance Driven by Tumor Microenvironment}

\author{
Peijie Wu ${ }^{1,2 t}$, Wei Gao ${ }^{2 \dagger}$, Miao Su' ${ }^{2}$ Edouard C. Nices ${ }^{3}$,Wenhui Zhang ${ }^{4}$, Jie Lin ${ }^{4 *}$ and \\ $\mathrm{NaXie}^{2 *}$ \\ ${ }^{1}$ School of Basic Medical Sciences, Chengdu University of Traditional Chinese Medicine, Chengdu, China, ${ }^{2}$ State Key \\ Laboratory of Biotherapy and Cancer Center, West China Hospital, and West China School of Basic Medical Sciences \& \\ Forensic Medicine, Sichuan University, and Collaborative Innovation Center for Biotherapy, Chengdu, China, ${ }^{3}$ Department \\ of Biochemistry and Molecular Biology, Monash University, Clayton, VIC, Australia, ${ }^{4}$ Department of Medical Oncology, \\ The Second Affiliated Hospital of Kunming Medical University, Kunming, China
}

Cancer is a disease which frequently has a poor prognosis. Although multiple therapeutic strategies have been developed for various cancers, including chemotherapy, radiotherapy, and immunotherapy, resistance to these treatments frequently impedes the clinical outcomes. Besides the active resistance driven by genetic and epigenetic alterations in tumor cells, the tumor microenvironment (TME) has also been reported to be a crucial regulator in tumorigenesis, progression, and resistance. Here, we propose that the adaptive mechanisms of tumor resistance are closely connected with the TME rather than depending on non-cell-autonomous changes in response to clinical treatment. Although the comprehensive understanding of adaptive mechanisms driven by the TME need further investigation to fully elucidate the mechanisms of tumor therapeutic resistance, many clinical treatments targeting the TME have been successful. In this review, we report on recent advances concerning the molecular events and important factors involved in the TME, particularly focusing on the contributions of the TME to adaptive resistance, and provide insights into potential therapeutic methods or translational medicine targeting the TME to overcome resistance to therapy in clinical treatment.

Keywords: therapeutic resistance, tumor microenvironment, adaptive resistance, exosome, immunotherapy, cancer-associated fibroblasts, vasculature system, hypoxia

\section{INTRODUCTION}

Cancer is a significant public health problem worldwide, with substantial incidence and mortality rates (Ferlay et al., 2019). There have been spectacular advances in the development and therapeutic application of treatment for tumors, including chemotherapy, radiotherapy, targeted therapy, and immunotherapy over the past several decades (Szakács et al., 2006). However, resistance to these therapies has been a major obstacle that restricts the effectiveness of cancer treatments and impacts patient survival (Liu et al., 2018). Therefore, most patients respond to therapies at an early stage, whereas patients at a later stage frequently display poor clinical outcomes with continuous treatment (Miller et al., 2019). A broad range of intrinsic mechanisms underlying how cancer cells escape from the cytotoxicity of tumor therapies have been revealed, including decreased 
drug accumulation, altered drug metabolism, mutated or altered drug target and enhanced DNA repair capability, as well as inactivated cell death signaling (Assaraf et al., 2019; Milman et al., 2019; Valencia and Kadoch, 2019; Zhong and Virshup, 2020). Tumor cell heterogeneity, especially cancer stem-like cells (CSCs), is another cause leading to various resistance responses for multiple therapies (Housman et al., 2014; Steinbichler et al., 2018). Accordingly, multiple studies have addressed intracellular response, including genetic or epigenetic alterations, for cell survival under the death pressure induced by therapies (Cheng et al., 2020; Jiang W. et al., 2020; Long et al., 2020; Wang et al., 2020). New viewpoints and theories have proposed that tumor progression, especially when confronted with external pressure from various therapies, is a dynamic and complicated process that tightly interacts with the surrounding environment (Hanahan, 2014).

The tumor microenvironment (TME) is the extracellular environment in which tumors cells exist, and consists of carcinogenetic cells, cancer-associated fibroblast (CAFs), immune cells [including $\mathrm{T}$ and $\mathrm{B}$ lymphocytes, tumor-associated macrophages (TAMs), and natural killer cells], the vasculature system, and the extracellular matrix (ECM; including secreted cytokine, chemokine, metabolites, and exosomes) (Quail and Joyce, 2013; Belli et al., 2018). It has been shown that the non-malignant cells in the TME are not just silent bystanders, but rather actively boost carcinogenesis by promoting excessive tumor initiation, malignant progression, metastasis, and therapeutic resistance (Mantovani et al., 2008; Grivennikov et al., 2010; Hanahan and Weinberg, 2011; Balkwill et al., 2012; Hanahan and Coussens, 2012). The transformed cancer cells are found to interact with stromal cells in the TME, which contribute extensively to tumor development and resistance. Additionally, hyperplasia, metabolic remodeling, malignant proliferation, and inhibition of apoptosis in tumor cells contribute to hypoxia, oxidative stress, and acidosis within the TME. These abnormal conditions further modulate the ECM to induce angiogenesis or mechanical stiffness, and ultimately result in metastasis and resistance (Schrader et al., 2011; Quail and Joyce, 2013; Maman and Witz, 2018; Lin et al., 2019). CAFs induce cancer progression as well as therapeutic resistance through the secretion of cytokines or chemokines, exosomes, and ECM remodeling factors (Shiga et al., 2015; Fu et al., 2016). Macrophages, adipocytes, and fibroblasts in the TME can also act as a sanctuary for tumor cells to escape immune elimination (Hui and Chen, 2015). Therefore, combination chemotherapy with drugs targeting the TME, such as immune cells and angiogenesis, has had success in clinical trials for overcoming drug resistance (Correia and Bissell, 2012; Jo et al., 2018).

Accordingly, an interesting concept has been proposed that the resistance of tumor cells to multiple therapies may be caused by both active (cell-autonomous) and adaptive (non-cellautonomous) mechanisms. While numerous active mechanisms of therapeutic resistance have been summarized previously, here, we focus on the adaptive resistance to various therapies mainly dependent on the TME (Figure 1) (Holohan et al., 2013; Housman et al., 2014). Furthermore, the complex reciprocity between tumors and TME and its role in adaptive resistance is discussed, with a perspective on prospects of overcoming therapeutic resistance.

\section{TME-DRIVEN ADAPTIVE MECHANISMS OF THERAPY RESISTANCE}

The TME contains a wide variety of cell types including CAFs, immune cells, and vascular cells embedded in the ECM. The TME also contains exosomes, metabolites and cytokines that mediate heterocellular interactions. Moreover, the physical or chemical features, including hypoxia, acidity, and oxidative stress, all facilitate tumor progression and resistance.

\section{Cancer-Associated Fibroblasts (CAFs)}

Cancer-associated fibroblasts are a prevalent subpopulation of cells in the tumor stroma (Orimo et al., 2005; Räsänen and Vaheri, 2010). The conversion from quiescence to activation of fibroblasts provokes various oncogenic signals that facilitate tumor cells to escape therapies (Kalluri and Zeisberg, 2006). Coculture of prostate tumor cells with CAFs attenuates doxorubicin cytotoxicity by obstructing DNA damage and suppressing ROS generation in tumor cells (Cheteh et al., 2017). CAFs may also be responsible for the resistance of therapy through secreting chemokines, growth factors, metabolites, and exosomes, causing resistance and recurrence (Figure 2) (Billottet et al., 2008; Kojima et al., 2010; Räsänen and Vaheri, 2010; Straussman et al., 2012). CAF-secreted PAI-1 activates the AKT and MAPK pathways in a paracrine way to reduce chemotherapy drug-induced DNA damage, ROS generation, and cell death in esophageal squamous cell carcinoma (ESCC) (Che et al., 2018). HGF secreted by CAFs can combine with the MET receptor to activate the PI3K-Akt and MAPK pathways, which is responsible for the resistance of BRAF inhibitors or EGFR inhibitors to glioblastoma, colon cancer, and melanoma (Thomasset et al., 1998; Luraghi et al., 2014; Fiori et al., 2019). In addition, CAF-derived paracrine signals including chemoattractant cytokines, metabolites, and exosomes induce the NF- $\kappa \mathrm{B}$ pathway, contributing to tumor cell resistance (Sun et al., 2012; Chan et al., 2016; Su et al., 2018; Zhang D. et al., 2018). Treatment with chemotherapeutic drugs upregulates WNT16B in CAFs, which mitigates the cytotoxic effects of drugs through the NF- $\kappa$ B pathway in prostate cancer cells (Sun et al., 2012). Similarly, secreted IL-1 $\beta$ and the constitutively expressed IL-1 receptor associated kinase 4 (IRAK4) induce the activation of the NF-кB pathway both in CAFs and pancreatic cancer cells, alleviating the cytotoxicity of gemcitabine in pancreatic tumors (Zhang D. et al., 2018). IL-6 is another cytokine released by CAFs that promotes cisplatin resistance through the STAT3/NF- $\mathrm{B}$ pathway by upregulating CXCR7 in ESCC (Qiao et al., 2018).

Given the pivotal role of CSCs in therapeutic resistance, the CAFs strengthen stemness as a route of acquired resistance (Zhao, 2016; Fiori et al., 2017). The IL-6 and IL-8 released by $\mathrm{CD}_{10}{ }^{+} \mathrm{GPR}_{7}{ }^{+}$CAFs can promote CSCs sustaining chemotherapy resistance in breast and lung tumors ( $\mathrm{Su}$ et al., 2018). Meanwhile, chemotherapy-treated colorectal CAFs promote the self-renewal of CSCs by increasing the secretion of interleukin-17A (IL-17A) (Lotti et al., 2013). In addition, 


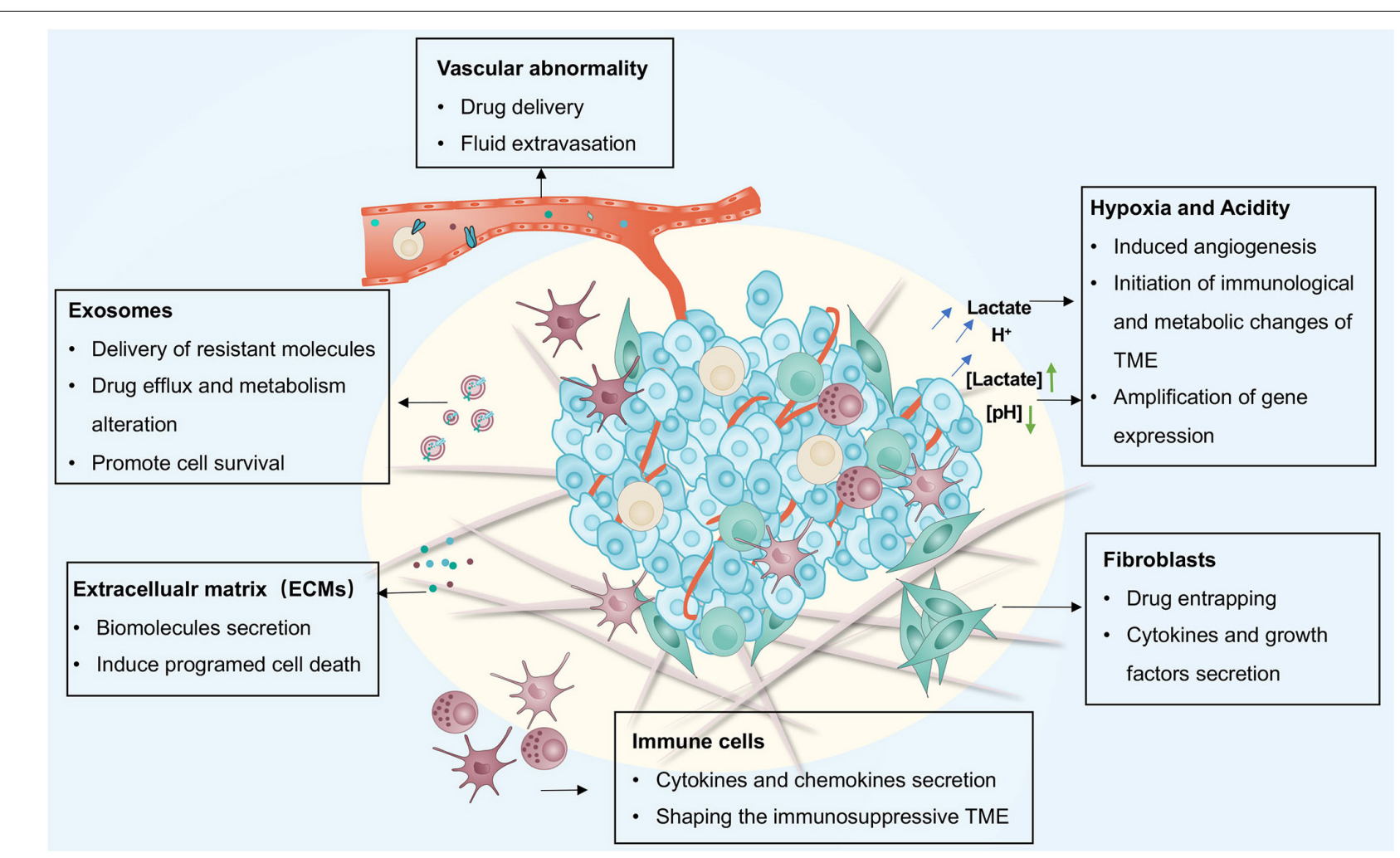

FIGURE 1 | The main adaptive mechanisms driven by the TME for therapy resistance including CAFs, immune cells, vasculature system, ECM, exosomes, hypoxia, and acidity. CAFs, cancer-associated fibroblasts; ECM, extracellular matrix.

TGF- $\beta 2$ secreted by CAFs cooperate with HIF-1 $\alpha$ derived from the hypoxic TME to activate the Hedgehog pathway, which promotes cancer cell stemness and resistance to chemotherapy (Tang et al., 2018). Moreover, ELF chemokines secreted by CAFs are also proven to induce the transformation of tumor cells to stem cells in breast and pancreatic tumors (Chan et al., 2016). The secretion of FGF5 by Hedgehog-activated CAFs in mouse models of breast cancer creates a supportive microenvironment for cancer cells by fostering a reversible stem-like phenotype. Indeed, inhibition of Hedgehog signaling by Smo inhibitors can hinder the transformation toward stemness status to recover the sensitivity of cancer cells to docetaxel (Cazet et al., 2018).

Furthermore, the complicated crosstalk between CAFs and tumor cells also contributes to resistance. For example, epithelial expression of platelet-derived growth factor (PDGF)-CC causes the CAFs to secrete STC1, IGFBP3, and HGF, which are responsible for the tamoxifen resistance in breast cancer (Roswall et al., 2018). To escape tumor treatment, the upregulated insulin receptor (IR) and insulin-like growth factor (IGF) 1 receptor (IGF1R) in cholangiocarcinoma (CCA) cancer cells promote the proliferation and activation of CAFs. CAF-secreted IGF2 provides a feedback pathway with IR/IGF1R to induce the resistance of cancer cells to erlotinib, a tyrosine kinase inhibitor (TKI). Hence, an IR/IGF1R inhibitor can improve the deleterious effect of erlotinib in xenografts models (Vaquero et al., 2018). Additionally, cancer cell-derived serum components, such as lysophosphatidic acid (LPA) and proteases, are reported to stimulate CAFs remodeling for tumor cells survival (Park et al., 2008; Yarnold and Brotons, 2010; Mantoni et al., 2011; Calvo et al., 2013). The remodeled CAFs, however, exert paracrine actions on tumor resistance via secreted growth factors, including VEGF-A, TGF- $\beta$, and various cytokines. CAFs-tumor cell contact can also activate the NOTCH signaling pathway, facilitating stroma-mediated radiotherapy (Freund et al., 2010; Acosta et al., 2013).

In general, the above evidence has shed light on the adaptive mechanism that CAFs utilize with tumor cells for acquired resistance in many cancers including lung, breast, prostate, and glioblastoma. CAFs can interact with various TME factors including immune cells, tumor cells, and the ECM to participate in tumor cell resistance. The heterogeneous nature of CAFs and their multiple functions are interesting potential research directions as they offer a promising strategy for novel cuttingedge therapies directed at tumors and the TME.

\section{Immune Cells}

The immune cells in the TME mainly consist of B cells, effector and regulatory $\mathrm{T}$ cells, TAMs, myeloid-derived suppressor cells (MDSCs), natural killer cells (NKs) as well as dendritic cells (DCs) (Chen F. et al., 2015; Lei et al., 2020). These cells are crucial for tumorigenesis, exerting either promoting or antagonizing effects on tumors (Lei et al., 2020). Cytotoxic $\mathrm{CD}^{+} \mathrm{T}$ cells 


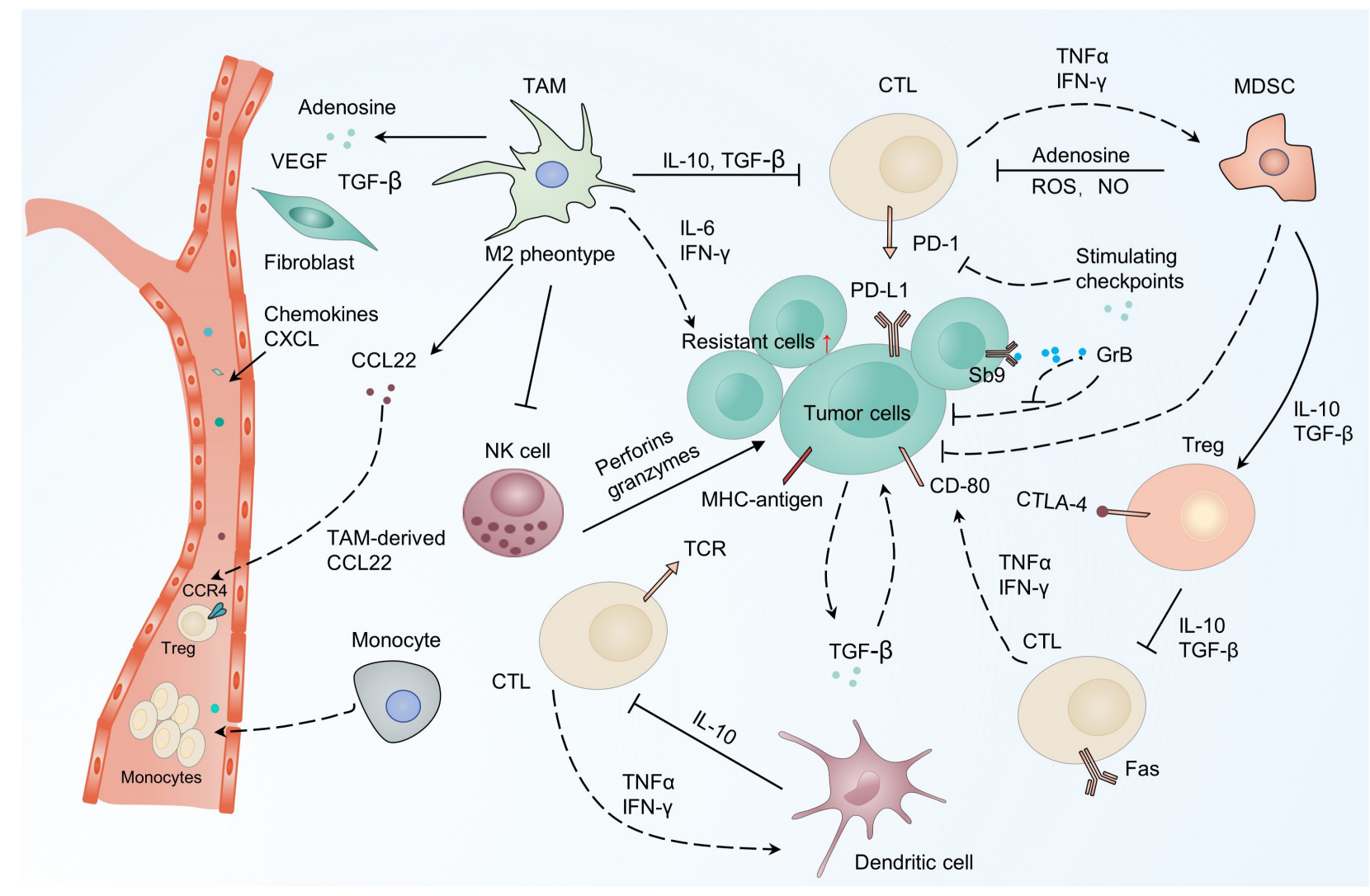

FIGURE 2 | Immune system response for resistance in the TME. Scavenging of tumor cells by the immune system is mainly mediated by CTLs which can be inhibited by cytokines and chemokines secreted by several types of immune cells in the TME. There are also many molecules on the tumor surface which contribute to exhausting, or even eliminating, anti-tumor immune cells like CTLs. TME, tumor micro-environment; CTLs, cytotoxic T cells.

(CTLs) are the primary lymphocytes for killing tumor cells. They secrete cytotoxic enzymes including perforin and granzyme, and can interact with the major histocompatibility complex I (MHCI) (Tanaka et al., 1999; Jackaman et al., 2012; Martínez-Lostao et al., 2015; Wei et al., 2018; Zhong et al., 2020). The involvement of CTLs in tumor therapeutic resistance is proven by the strong association between the profile of CTLs in tumors and the chemotherapy outcomes (Figure 3) (Denkert et al., 2010; Halama et al., 2011; Chen and Chang, 2019). In ovarian cancer, CTLs can enhance the immunogenic action of IFN- $\beta$ to abrogate CAFmediated resistance to platinum-based chemotherapy (Wang et al., 2016). Indeed, the combination of cisplatin with immune checkpoint inhibitors (ICIs) have been shown to result in better clinical outcomes (Gandhi et al., 2018; Socinski et al., 2018). TAMs are one of the most abundant cells detected in solid tumors and are derived from circulating monocytes. They also play an important role in controlling the immunosuppressive mechanisms of the TME, contributing to tumor development and therapeutic resistance (Solinas et al., 2010; Ruffell and Coussens, 2015; Räihä and Puolakkainen, 2018; Salmaninejad et al., 2019; Saleh and Elkord, 2020). Evidence implicates TAMs in the secretion of cytokines including IL-6 and IFN in response to resistance (Jinushi et al., 2011; Salvagno et al., 2019). Blocking colony stimulating factor 1 receptor (CSF-1R) signaling to regulate the polarization status of TAMs has been found to be an effective way of restoring the sensitivity of cisplatin involving IFN response (Salvagno et al., 2019). Accordingly, these promising results have encouraged the evaluation of combination therapy strategies targeting the immune system for tumor patients.

Growing evidence suggests that immunotherapy has shown dramatic efficacy in clinical outcomes (Wei et al., 2018; Cervantes-Villagrana et al., 2020). However, some cancer patients treated using this approach show limited response rates due to acquired resistance (O'Donnell et al., 2017; Sharma et al., 2017). It has been shown that acquired immune resistance may be achieved by three approaches: (i) increased levels of immunosuppressive cells and molecules; (ii) upregulation of immune checkpoints; and (iii) tumor mutation loads and loss of target antigens. For example, enhanced recruitment of immunosuppressive cells, such as TAMs and MDSCs, reduces the sensitivity of immunotherapy and enhances immunosuppression, leading to acquired resistance (Restifo et al., 2016; O'Donnell et al., 2017; Sharma et al., 2017). Maj et al. (2017) have demonstrated that apoptotic Tregs can upregulate the level of extracellular adenosine which can be correlated with acquired resistance to anti-PD-L1 mAb treatment in mice models. Moreover, the compensatory inhibitory mechanism also contributes to acquired resistance. For instance, increased 


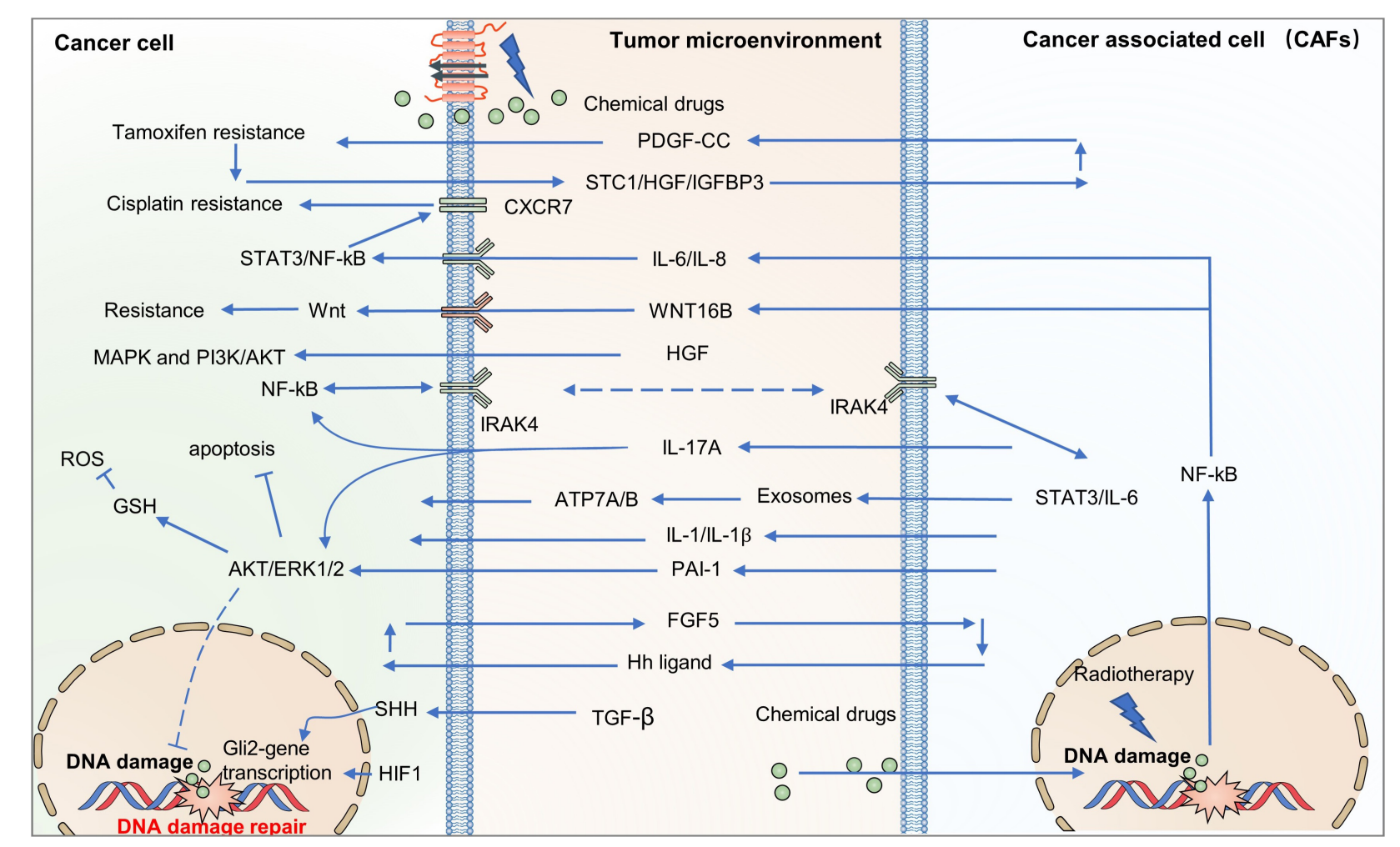

FIGURE 3 | CAFs drive resistance-related paracrine pathways in the TME. CAFs provide an adaptive response for resistance by secreting chemokines, growth factors, metabolites, and exosomes, which activate various signaling pathways in cancer cells, including PI3K-Akt/MAPK, NF- $\mathrm{KB}$, and STAT3. PI3K-Akt, the phosphatidylinositol 3-kinase (PI3K)/protein kinase B (AKT) signaling pathway; MAPK, mitogen-activated protein kinase pathway; NF-кB, nuclear factor-кB; STAT3, signal transducer and activator of transcription 3.

$\mathrm{CD} 4^{+} \mathrm{TIM}^{-} 3^{+}$and $\mathrm{CD} 8^{+}$TIM-3 ${ }^{+}$T cells in lung tumor biopsies has been related with resistance to anti-PD-1 mAb in both humans and mice (Koyama et al., 2016). Similarly, increased TIM-3 on CTLs has been reported in HNSCC following treatment with anti-PD-1 mAb (Shayan et al., 2017). The alteration of neoantigens may be another reason for acquired resistance, as manifested by the fact that loss of CD19 causes resistance following CD19-CAR-T cell therapy (Shalabi et al., 2018). Interestingly, the latest studies implicate that the serine protease inhibitor SerpinB9 (Sb9), expressed in CAFs, MDSCs, and TAMs, can promote tumor cell proliferation by combining with granzyme B $(\mathrm{GrB})$ leading to resistance to immunotherapy (Mangan et al., 2017; Jiang L. et al., 2020; Yin et al., 2020).

\section{Vasculature System}

Numerous studies have shown that the responsiveness of tumors to therapy is affected by the vasculature system. Mechanically, the vasculature influences drugs transportation and sensitivity by controlling the supply of nutrients and oxygen, ultimately regulating tumor cell survival (Galmarini et al., 2000). The vasculature transports nutrients and oxygen, as well as other growth factors, to both normal and tumor tissue, and removes waste products following cellular metabolism, which can be involved in tumor relapse, metastasis, and resistance. Vessels in tumors are observed to be convoluted, branched, and dilated, with excessive loops compared with normal tissues (Jain, 1988). In some cases, vessels cannot be transformed into capillaries, arterioles, or venules. Moreover, vessel walls are often discontinuous or absent compared with normal tissues leading to varying degrees of leakiness in different tumors (Benjamin et al., 1999; Carmeliet and Jain, 2000; Hashizume et al., 2000; Yonenaga et al., 2005; Trédan et al., 2007). Accordingly, blood flow in tumors becomes chaotic and variable (Carmeliet and Jain, 2000). In the tumor vascular network, the viscosity and geometric resistance of blood is increased, and the pressure between arterioles and venules is depressed (Sevick and Jain, 1989; Trédan et al., 2007). Further, in normal tissues, pressure is reduced via the lymphatic network. However, lymph vessels are found to be lacking or have reduced functionality in solid tumors compared with normal tissues, leading to higher interstitial pressure (Leu et al., 2000; Stohrer et al., 2000; Heldin et al., 2004; Trédan et al., 2007). This higher interstitial pressure can suppress the transportation and distribution of larger biological molecules, and diverts blood away from the center toward the periphery of the tumor (Salnikov et al., 2003; Heldin et al., 2004). Interestingly, even in the same tumor, the rate of blood flow or morphology of vessels may vary with space and time (Gillies et al., 1999; Vaupel, 2004). These aberrant vasculature systems, and the dimensional compression of vessels caused by the excessive proliferation of tumor cells, reduce the rate of blood flow and impair the nutrition 
and oxygen supply to the tumor tissues (Padera et al., 2004). The insufficient supply of nutrients and oxygen as well as clearance of metabolic waste creates an acidic and hypoxic TME, which promotes therapeutic resistance (Tatum, 2006).

Further, the synergistic effect of various cell types in the TME, such as pericytes, endothelial cells, and bone marrowderived progenitors, is the basis of tumor angiogenesis, which is reported to be sensitive to oxygen levels (Weis and Cheresh, 2011; Semenza, 2013). Mesenchymal stem cells (MSCs), TAMs, and CAFs all promote tumor angiogenesis by releasing various angiogenesis-related ligands. For instance, increased VEGFA is associated with poor prognosis in metastatic tumors such as lung, colon, and renal cell carcinomas (Hegde et al., 2013; Lee and $\mathrm{Wu}, 2015$ ).

The delivery of drugs is also compromised by these aberrant vasculature systems (Durand, 2001). The infiltration gradient in the spatial distance from vascular components to tumor lesions is related to the distribution of drugs from the tissues to cancer cells. Microvascular density (MVD) is an important index for the clinical outcomes of carcinomas of the lung, breast, and liver (Trédan et al., 2007; Ariotti et al., 2015; Yuan et al., 2015). Growing evidence indicates that VEGF receptor inhibitor resistance is mainly caused by proangiogenic factors, suggesting that combination with anti-angiogenic agents may improve clinical outcomes compared with VEGF receptor inhibitors alone (Flaherty et al., 2015). In addition, the chemokine CXC motif ligand receptor (CXCR7) is reported to promote angiogenesis by increasing ERK1/2 phosphorylation (Yamada et al., 2015). Interestingly, the CXCL12-CXCR7 complex has been shown to mediate pro-angiogenesis, tumor growth, lung metastasis, and resistance (Yamada et al., 2015; Sun, 2016). Accordingly, antiangiogenesis may be an affective therapy by specifically targeting tumor blood vessels.

\section{Extracellular Matrix (ECM)}

The ECM consists of fibrous protein (such as laminin, elastin, and collagen), proteoglycans, water, and microelements, weaving a complex fiber-based network to provide structural support and regulate cellular activities, including proliferation, communication, and adhesion (Watnick, 2012; Martino et al., 2014; McAndrews et al., 2015; Korneev et al., 2017; Walker et al., 2018). In tumors, both the composition and physical or chemical properties of the ECM are different, depending on the tumor tissue, resident cells, tumor staging, and therapeutic strategies (Shree et al., 2011; Correia and Bissell, 2012; Watnick, 2012; Klemm and Joyce, 2015; Sato et al., 2016; Korneev et al., 2017; Jo et al., 2018; Senthebane et al., 2018; Walker et al., 2018). The ECM contributes to tumor resistance by influencing drug delivery, facilitating the escape from immune surveillance, and manipulating the transmembrane signaling transduction process.

Drugs are usually transported to the tumor issues by the pressure of blood circulation through interstitial areas. In this process, drugs need to cross the physical and biochemical barriers of the TME. The desmoplastic stroma has been found to be a barrier responsible for drug resistance by impeding the delivery of anti-cancer drugs and affecting vascular systems in tumors (Olive et al., 2009). In interstitial spaces, the organization of the ECM has been found to increase fluid pressure due to the barriers of the tumor mass, significantly suppressing the efficacy of drug delivery (Correia and Bissell, 2012; Maeda and Khatami, 2018). Moreover, excessive proliferation of cancer cells promotes fluid flux from the neoplasms toward the surroundings which impedes drug transportation (Chen Y. et al., 2019). Indeed, drug delivery efficiency has been demonstrated to be inhibited in the $3 \mathrm{D}$ cultured spheroids compared with the $2 \mathrm{D}$ monolayer owing to the density of the ECM cells (Jo et al., 2018). Furthermore, tumor cells within the collagen I matrix display obvious resistance when cells are exposed to 5-fluorouracil/oxaliplatin (Kanazawa et al., 2017; Jo et al., 2018; Matsunuma et al., 2019).

Besides influencing drug delivery, the ECM also plays an essential role in controlling cytokine activity, of which TGF- $\beta$ is the most important. TGF- $\beta$ induces the recruitment of fibroblasts to the tumor site and transformation to CAFs by regulating ECM matrix degradation (Itoh et al., 2017; Paauwe et al., 2018; Purcell et al., 2018). In addition, TGF- $\beta$ along with HIF-1 can induce lysyl oxidase (LOX) which orchestrates ECM stiffness by inducing cross-linked collagen (Dauer et al., 2018; Zhao et al., 2018). ECM stiffness, in turn, can activate the TGF- $\beta$ signaling pathway to form a bridge in the basement membrane and contribute to tumor cell evasion (Upagupta et al., 2018; Najafi et al., 2019). Indeed, genomic and transcriptomic analysis have demonstrated that the activated gene sets in response to TGF- $\beta$ signaling are involved in regulating various pathophysiological processes including EMT, wound healing, angiogenesis, and dissemination (Hugo et al., 2016). On the other hand, TGF- $\beta$ can regulate immune response by orchestrating the crosstalk of multiple cell types in the TME, including CAFs, lymphocytes, and endothelial cells (Korneev et al., 2017; Chakravarthy et al., 2018; Kesh et al., 2020). TGF- $\beta$ can inhibit the proliferation and differentiation of anti-tumor $\mathrm{T}$ cells by increasing the expression of CD25 and Foxp3 (Löffek, 2018). Moreover, TGF- $\beta$ induces the secretion of monocyte chemoattractant protein-1 (MCP-1) to upregulate the expression of mesenchymal markers and chemotactic factors (CCL-2, 7, 8, 13), which are associated with anti-PD-1 immune resistance (Díaz-Valdés et al., 2011; Sawa-Wejksza and KandeferSzerszeń, 2018).

Among the multiple TME factors that impact cancer cell therapy resistance, cell adhesion to the ECM has been considered as a key determinant (Eke and Cordes, 2015). In particular, cell adhesion-mediated drug resistance depends on interactions between integrins and ECM components such as collagen, fibronectin, and laminin (Grivennikov et al., 2010; Hanahan and Weinberg, 2011; Korneev et al., 2017; Arneth, 2019; Cassim and Pouyssegur, 2019). Integrin-mediated resistance has been reported to influence chemical drugs, radiotherapy, and targeted therapies such as TKIs (Goel et al., 2013; Seguin et al., 2014). It has been reported that the treatment of fibronectin or collagen-deficient ECMs with cisplatin increases the sensitivity of tumor cells by about $40 \%$ (Senthebane et al., 2018). The loss of integrin subunits, such as $\alpha v \beta 3$ or $\alpha v \beta 5$, can significantly restore the sensitization of glioblastoma and breast tumor cells to radiotherapy (Cao et al., 2006; Belli et al., 2018). The silencing of the $\alpha \mathrm{v}$ subunit also increases the efficacy of oxaliplatin in colon tumor cells (He et al., 2009; Cruz da Silva et al., 2019). 
Additionally, the over-expression of $\beta 1$ integrin significantly inhibits cell death in hepatocellular carcinoma exposed to etoposide, cisplatin, or docetaxel (Zhang et al., 2002, 2019; Ogawa et al., 2008). Mechanically, integrins transmit the signals in the microenvironment into intracellular pathways through focal adhesion kinase (FAK) and integrin-linked kinase (ILK) (Eke and Cordes, 2015). The complexes of FAK, ILK, cortactin, and cysteine-histidine-rich 1 as well as parvin $\alpha$ have been reported to inhibit the outcome of radiotherapy (Eke and Cordes, 2015). Integrin $\beta 1$ regulates the dephosphorylation of FAK to protect tumor cells resistant to radiotherapy in a JNK-dependent manner on HNSCC and PDAC in vitro and in vivo (Goel et al., 2013; DeRita et al., 2019). Blocking the $\alpha 5 \beta 1$ subunit reduces the resistance to ellipticine and temozolomide dependent on p53 mutation status in glioblastoma cells (Martinkova et al., 2010; Fujita et al., 2020). Upregulated $\alpha 4$ integrin is responsible for the resistance in AML and esophageal cancer cells via the PI3K/Akt pathway (Layani-Bazar et al., 2014; Chen and Chang, 2019; Cruz da Silva et al., 2019). Additionally, a few findings suggest that the NF- $\mathrm{B}$ or ILK-RhoB pathways may be involved in integrin-mediated resistance (Monferran et al., 2008; Ahmed et al., 2013). The ECM proteoglycan, versican, can impact immune surveillance evasion along with hyaluronan by increasing the expression of inflammatory cytokines such as IL-6, TNF $\alpha$, and NF- $\mathrm{BB}$ (Kang et al., 2017; Gordon-Weeks and Yuzhalin, 2020; Wight et al., 2020; Gamradt et al., 2021). Taken together, the complexity of the ECM in composition and structure as well as heterogeneity still needs to be further understood for therapeutic purposes.

\section{TME-Derived Exosomes}

Exosomes or extracellular vesicles (EVs) with sizes of 40 to $100 \mathrm{~nm}$, originating from large multivesicular bodies (MVBs), mediate cell-to-cell communication by transferring biologically active cargo, including DNAs, RNAs, proteins, and metabolites (Schneider and Simons, 2013; Sun, 2016; Mashouri et al., 2019). Exosomes have been demonstrated to be crucial signaling mediators in the TME, participating in tumorigenesis, metastasis, TME remodeling, angiogenesis, and therapeutic resistance (Figure 4) (Luga et al., 2012; Yoshizaki et al., 2013; Jeppesen et al., 2014; Sung et al., 2015; You et al., 2015; Paolillo and Schinelli, 2017; Wang X. et al., 2018; Zeng et al., 2018; Mashouri et al., 2019; Steinbichler et al., 2019; Yang E. et al., 2020). For example, exosomes have been found to control metabolic reprogramming (Yang E. et al., 2020). Exosomes can also scavenge unfavorable molecules in normal cells. Cancer cells hijack exosomes for the efflux of anti-cancer drugs, resulting in drug resistance (Safaei et al., 2005). Thus, drug-resistant ovarian carcinoma cells exhibit an enhanced exosomal export of cisplatin together with putative transporters MRP2, ATP7A, and ATP7B (Safaei et al., 2005).

Exosomes and their cargos can also promote the drug resistance of target cells (Shedden et al., 2003; Corrado et al., 2013). Exosomes extracted from resistant breast and

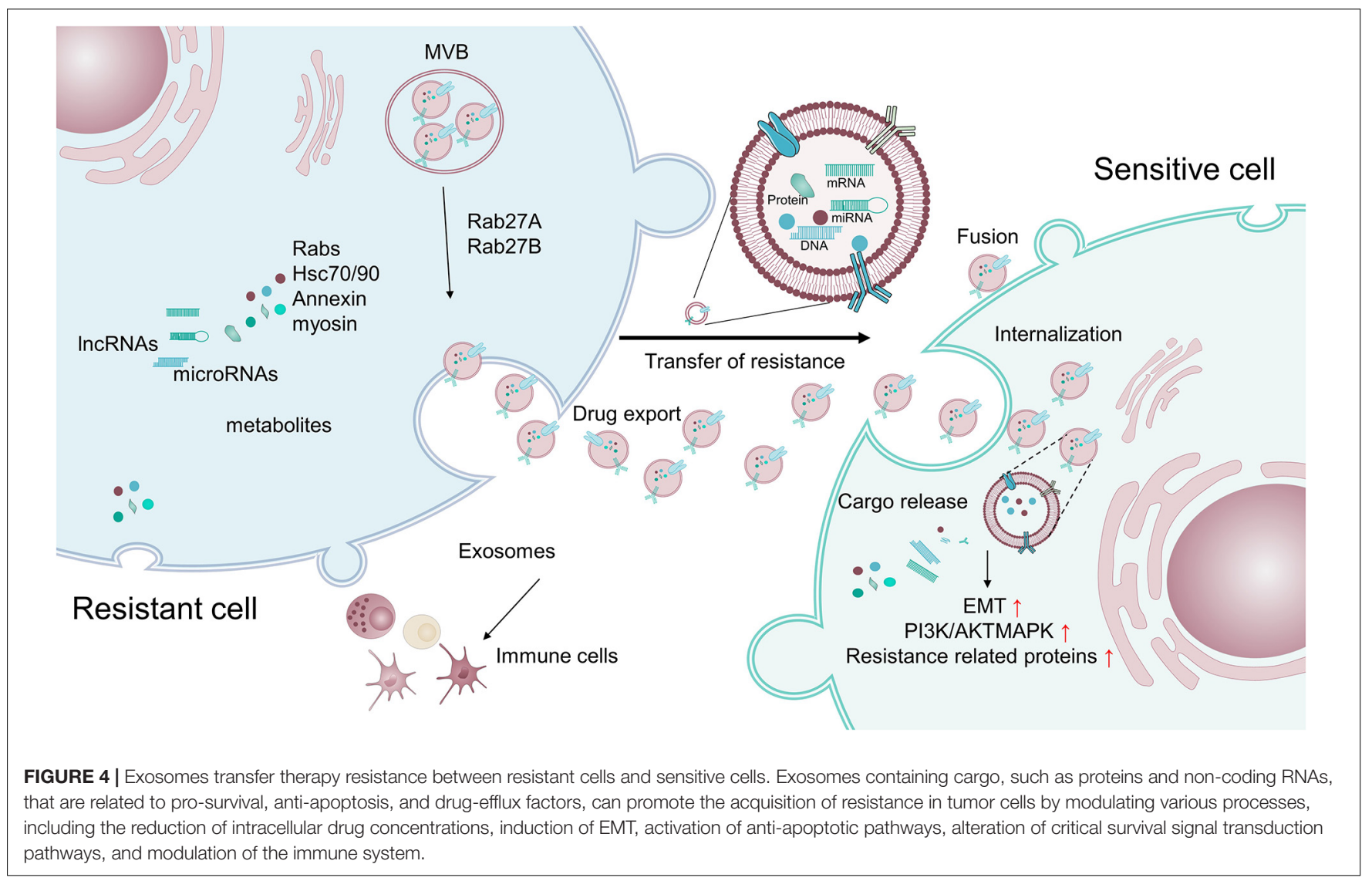


prostate cancer cells have been shown to contain MDR1/Pgp transporters, conferring resistance to drug-sensitive tumor cells (Levchenko et al., 2005; Corcoran et al., 2012; Lv et al., 2014). miR-155 in exosomes has been reported to induce chemoresistance by increasing the FOXO-3a, TGF- $\beta$, and C/EBP$\beta$-mediated expression of EMT markers (Du and Shim, 2016; Crow et al., 2017; Lobb et al., 2017; Wang et al., 2019). Notably, exosomes isolated from triple-negative breast cancer cells can induce drug resistance on non-tumorigenic breast cells by modulating the PI3K/AKT, MAPK, and HIF1A pathways (Ozawa et al., 2018). Additionally, lymphoma exosomes carrying CD20 shield target cells form an antibody attack via the complement consumption of therapeutic anti-CD20 antibodies, leading to evasion of humoral immunotherapy (Aung et al., 2011).

Intriguingly, exosomes also promote therapeutic resistance by facilitating the intricate crosstalk between tumor cells and nontumor cells within the TME. RNAs within exosomes derived from stromal cells activate the pattern recognition receptor RIG-I and downstream STAT1 signaling, which facilitates the growth of resistant tumor cells (Boelens et al., 2014). Exosomes secreted by TAMs transfer miR-21 to gastric cancer cells, which activates the PI3K/AKT signaling pathway and suppresses cell apoptosis to confer resistance (Zheng et al., 2017). Meanwhile, TAMs can directly deliver mRNAs to enhance the expression of CDK6, mTOR, STAT3, and $\beta$-catenin, leading to cisplatin resistance in $\mathrm{BCa}$ cells ( $\mathrm{Wu}$ et al., 2020). In another example, exosomes released from CAFs strengthen the chemo-resistance of pancreatic cancer cells and colorectal cancer cells by activating $\beta$-catenin and the Snail pathway (Richards et al., 2017; Ren et al., 2018).

Collectively, exosomes can cause tumor cells to acquire resistance by various pathways, including the reduction of intracellular drug concentrations, induction of EMT, activation of anti-apoptotic pathways, alteration of critical survival signal transduction pathways, and modulation of the immune system (Mashouri et al., 2019; Steinbichler et al., 2019; Dai et al., 2020).

\section{Hypoxia, Acidity, and Oxidative Stress}

The abnormal vasculature and heavy requirement for oxygen in tumors create a chronic or diffusion-limited hypoxia and acid environment (Bussink et al., 2003; Heldin et al., 2004; Milosevic et al., 2004; Gargiulo et al., 2019; Zaidi et al., 2019). The hypoxic environment of tumors leads to a decreased supply of nutrients such as glucose and essential amino acids (Lee et al., 2014; Tan et al., 2015; Ma et al., 2020). Moreover, tumor cells prefer to undergo glycolysis rather than oxidative metabolism which often converts glucose to lactate for the production of ATP, resulting in sequential acidic microenvironments (Dang and Semenza, 1999; Singh et al., 2017; Moloney and Cotter, 2018). Furthermore, a decreased capability of removing these acidic products results in low interstitial $\mathrm{pH}$, another feature of solid tumors (Tran et al., 2016; Singh et al., 2017). These hypoxic and acidic conditions will induce aberrant activation of oncogenic pathways and genetic instability, contributing to tumor development and resistance (Li and Sun, 2018). For example, hypoxia in tumors increases the expression of multiple genes associated with angiogenesis and cell survival by activating HIF-1, a basic helix-loop-helix transcription factor (bHLH) (Pouysségur et al., 2006; Chen and Sang, 2016; Petrova et al., 2018; Lee et al., 2020). Serving as an oxygen sensor, HIF-1 may promote the expansion of tumor cell populations and alteration of biochemical metabolites involved in a resistant phenotype in response to hypoxia. It has been shown that hypoxia reduces sensitivity to p53-mediated apoptosis and promotes chemotherapeutic resistance in tumor cells (Kinoshita et al., 2001; Holle et al., 2016; Ritter, 2017). In solid tumors, the activation of major oncogenic signaling pathways such as Ras and PI3K/AKT, and the silencing of tumor suppressors LKB1, PTEN, and TSC2/1 can activate HIF-1, contributing to resistance (Shaw et al., 2004; Shackelford et al., 2009). Stabilization of $\mathrm{HIF}-1 \alpha$ through interaction with $\mathrm{Hsp} 90 / \mathrm{Hsp} 70$ also facilitates cell survival under stress conditions (Luo et al., 2010; Taipale et al., 2010). Additionally, HIF-1 $\alpha$ can cooperate with CAFsecreted TGF- $\beta 2$ to induce GLI2 signaling cancer stem cells, leading to enhanced stemness and chemotherapy resistance (Tang et al., 2018).

Mechanically, HIF-1 activation induces the transcription of genes that facilitate pathophysiological alterations related to resistance, including the suppression of apoptosis and the induction of drug efflux and metabolism (Warfel and El-Deiry, 2014; Xia et al., 2018). Apoptosis may be a major factor in cell death induced by chemo- or radio- therapies (Krakstad and Chekenya, 2010; Mohammad et al., 2015; Zhao et al., 2015). Interestingly, HIF- $1 \alpha$ has been found to both inhibit proapoptotic proteins, including TRAIL, and activate anti-apoptotic proteins, such as survivin, c-myc, STAT3, and TCF4, to promote the survival of tumor cells under chemo- or radio- therapies (Pei et al., 2010; Rohwer et al., 2010; Nishimoto et al., 2014; Zhao et al., 2016). HIF-1 $\alpha$ also influences sensitivity to therapy through regulation of genes related to metabolic pathways (Lu et al., 2011; Meijer et al., 2012; Huang et al., 2013). HIF-1 $\alpha$ can upregulate GLUT-1 to promote glycolysis, leading to increased intracellular ATP, pyruvate, and lactate levels (Meijer et al., 2012), while the suppression of HIF- $1 \alpha$ results in a reduced glucose uptake, decreased lactate production, and increased oxygen species (ROS), which contribute to the enhanced efficacy of radiotherapy (Meijer et al., 2012). Hypoxia has been reported to promote temozolomide (TMZ) resistance in glioblastoma multiforme (GBM), through the activation of HIF- $1 \alpha$ and NF- $\kappa$ B, followed by upregulated expression of Bcl-xL (Kitange et al., 2009; Chen W.L. et al., 2015). Transient hypoxia has also been found to cause an increase in dihydrofolate reductase and P-glycoprotein, which contributes to the resistance of drugs targeting topoisomerase II (Kovacic and Osuna, 2000; Gray et al., 2005). Interestingly, oxygen concentration may affect the efficacy of the anti-cancer drugs doxorubicin and mitomycin $\mathrm{C}$, by delivering electrons to the oxygen (Brown and Wilson, 2004; Trédan et al., 2007; Yang G. et al., 2020).

Acidity in the TME has been demonstrated to affect the efficacy of various therapies. It can influence the transport of chemical drugs across the membrane due to the $\mathrm{pH}$ gradient caused by the acidic extracellular $\mathrm{pH}$ and near neutral or alkaline intracellular $\mathrm{pH}$ in tumors (Gerweck et al., 2006; Trédan et al., 2007). Hence, drugs with an acidic dissociation constant of 7.5-9.5 may show a significantly reduced rate of uptake, 
such as vincristine, mitoxantrone, doxorubicin, and vinblastine (Cowan and Tannock, 2001; Gerweck et al., 2006; Trédan et al., 2007; Zhou et al., 2019). Therefore, the cytotoxicity of these drugs is suppressed, resulting in a resistant phenotype (Raghunand et al., 2003; Trédan et al., 2007; Stepka et al., 2020). However, the concentration of some weakly acidic drugs including cyclophosphamide and chlorambucil may be increased in the neutral intracellular region (Gerweck et al., 2006; Trédan et al., 2007). Moreover, an acidic TME also alters the cellular proteome, cellular metabolism, and signaling pathways, facilitating stemness and drug resistance in cancer cells. The acidosis induces SOX2 expression by inhibiting vitamin D receptor (VDR)-mediated transcription, resulting in drug resistance (Hu et al., 2020). Enhanced lactate uptake and oxidation-induced lactic acidosis foster the resistance to uprosertib, a pan-Akt inhibitor, in colon cancer cells (Barnes et al., 2020). Moreover, the acidic environment induces the activity of p-glycoprotein ( $\mathrm{pGP}$ ) by activating p38 signaling, leading to multi-drug resistance in rat prostate cancer cells (AT1) (Sauvant et al., 2008). Clearly, the acidity of the TME must be considered when designing the delivery of drugs to obtain maximal therapeutic effect.

Oxidative stress is another feature of the TME, which is caused by the overproduction of reactive oxygen species (ROS) from both tumor cells and non-malignant cells in the TME. Oxidative stress plays a pivotal role in tumor progression, particularly through immune cell suppression. ROS downregulates the antitumor functions of effector immune cells that are recruited to the tumor site, notably $\mathrm{T}$ lymphocytes and natural killer (NK) cells which mediate anti-tumor immunity. MDSCs have been found to inhibit $\mathrm{T}$ cell proliferation to promote colorectal cancer cell proliferation by increasing ROS levels (OuYang et al., 2015; Weinberg et al., 2019). ROS and peroxynitrite in MDSC trigger the nitration of the TCR/CD8 complex which inhibits its interaction with $\mathrm{pMHC}$, contributing to $\mathrm{T}$ cell tolerance and tumor escape (Nagaraj et al., 2007). ROS generated from NOX2sufficient myeloid cells inhibits the NK cell-mediated clearance of malignant cells, facilitating the metastasis of melanoma cells (Aydin et al., 2017). The NK cells residing in the tumor core or primed by IL-15 exhibit higher thiol densities that can prevent other lymphocytes from ROS within the TME (Yang Y. et al., 2020). High levels of ROS following TCR and CD28 stimulation enhance Treg cell-mediated tumor immunosuppression and attenuate anti-tumor $\mathrm{T}$ cell responses by stabilizing SENP3 (Yu et al., 2018). In conclusion, oxidative stress acts as an important mediator of anti-tumor immunity. Achieving targeted oxidative stress could be a potential strategy to improve the efficacies of existing immunotherapy treatment.

\section{Heterocellular Metabolic Interactions}

Growing evidence has demonstrated that disordered metabolism in the TME plays a crucial role in malignancy, metastasis, and immune resistance. The impact of metabolism on immuneresistance is mainly caused by two aspects: a reshaped immunosuppressive TME from tumor metabolic stress and immune-inhibiting metabolites generated by tumor cells.

Cancer cells usually exhibit high rates of glycolysis and aggressive depletion of amino acids such as tryptophan, arginine, and glutamine compared with normal cells. Tumor metabolic stress modulates the metabolic properties of malignant cells, which in turn influences nutrient shortage, oxygen competition, and acidity in the TME to create an immune-resistant environment (Martinez-Outschoorn et al., 2017). It is known that the demand for nutrients is especially high in TME, and this nutrient competition can impair the anti-cancer immune response. For example, the competition of carbohydrates can inhibit the anti-tumor effect of cytotoxic $\mathrm{T}$ cells by inducing the expression of immunosuppressive cytokines and immune checkpoint inhibitors (Wu et al., 2021). The restriction of glucose supplies due to the high rates of glycolysis in tumor cells impairs the anti-tumor function of $\mathrm{CD} 4^{+} \mathrm{T}$ cells, possibly by blocking the secretion of IFN- $\gamma$ (Chang et al., 2015; Ho et al., 2015). Similarly, L-arginine deprivation has been found to inhibit antitumor immunity by inducing MDSC infiltration or suppressing the toxicity of IFN- $\gamma$. L-arginine depletion also promotes the immune evasion of cancer cells by elevating the tumoral level of PD-L1 (Morrow et al., 2013; Fletcher et al., 2015; Hugo et al., 2016; Prima et al., 2017; Kim et al., 2018; Jiang Z. et al., 2020). Tryptophan is another crucial amino acid that contributes to the anti-tumor immune response by regulating the kynurenine metabolic pathway (Jiang Z. et al., 2020; Xie et al., 2020). Indoleamine 2,3-dioxygenase (IDO), an essential enzyme of the tryptophan metabolic pathway, controls the production of kynurenine which exerts immunosuppressive effects by inducing differentiation of $\mathrm{T}$ cells and reduces immunogenicity (Wang et al., 2015; Ramapriyan et al., 2019). Both inhibitory immune cells such as MDSCs, DCs, and M2 macrophages as well as tumor cells can express IDO (Ramapriyan et al., 2019). Cancer cells have also been found to reduce tryptophan levels in TME to inhibit immune response (Ramapriyan et al., 2019). Besides glucose and amino acid metabolic pathways, lipid-related metabolism also plays an essential regulatory role in immunosuppressive function (Kamphorst et al., 2013). Obesity induces a desmoplastic TME by promoting inflammation and TAN infiltration, leading to impaired response to chemotherapy in PDAC. Reversal of obesity-aggravated desmoplasia by blocking the angiotensinII type-1 receptor (AT1) improves response to chemotherapy. Meanwhile, cholesterol depletion can also recover the cytotoxic effect of chemical agents on PDAC and HCC (Guillaumond et al., 2015; Incio et al., 2016). Fatty acids have also been demonstrated to determine the cell fate of $\mathrm{T}$ cells and $\mathrm{CD} 8^{+}$effector $\mathrm{T}$ cells (O’Sullivan et al., 2014).

In addition, a variety of tumor metabolites have been reported to promote immune evasion. Glutamine is the most abundant amino acid in the TME, playing an essential role in anabolic growth and metastasis (Pusch et al., 2017; Zhang et al., 2017). Recent research has demonstrated that glutamine metabolism can impair anti-cancer immune response (Zhang et al., 2017; Oh et al., 2020). Glutamine blockade causes increased glucose and glutamine levels in the TME, inducing MDSCs apoptosis, promoting their differentiation toward the M1 type, and sensitizing resistant tumor cells to immunotherapies (Zhang et al., 2017; Leone et al., 2019; Oh et al., 2020). Adenosine, the breakdown production of ATP, can active the adenosine-AR pathway to escape from the killing effects of the immune system 
by reducing the response of NK cells, M1 macrophages, and $\mathrm{CD}^{+}$effector $\mathrm{T}$ cells. In addition, methylglyoxal (MG), a sideproduction of glycolysis, is an immunosuppressive metabolite that promotes tumor cell growth and resistance (Nokin et al., 2017; Antognelli and Talesa, 2018; Antognelli et al., 2019; Oh et al., 2020). The high concentration of methylglyoxal in the TME derived from MDSCs leads to the accumulation of methylglyoxal in $\mathrm{T}$ cells, contributing to anti-tumor evasion (Baumann et al., 2020). DMBG ( $N$ - $N$-dimethylbiguanide) can recover the sensitivity of immunotherapy-resistant tumor cells by removing the glycation activity of methylglyoxal (Baumann et al., 2020). Another molecule that can establish an immunosuppressive TME is lactate, a product of glycolysis and glycogenolysis (Gabrilovich et al., 2012; Mantovani et al., 2017; Pucino et al., 2017; Tong et al., 2018; García-Cañaveras et al., 2019). Lactate induces the development of MDSCs, polarization of macrophages into an immunosuppressive phenotype, maturation of DCs, and inhibition of effector $\mathrm{T}$ cells, thereby promoting immune evasion (Husain et al., 2013; Brand et al., 2016; Laoui et al., 2016; Angelin et al., 2017; Morrot et al., 2018). Furthermore, lactate can control CAFs to produce growth factors including hyaluronan (Wu et al., 2017; Apicella et al., 2018; Feichtinger and Lang, 2019).

Collectively, tumor cells reshape their metabolism adaptively which leads to the remodeling of the TME. The heterocellular metabolic interactions create an immunosuppressive TME, which subsequently enhances tumor proliferation and immunetherapy resistance. Thus, targeting tumor cell metabolism or metabolites in the TME should have great potential for recovering immunotherapy resistance.

\section{The Epithelial Pathway in Response to TME}

It is well known that tumor initiation and progression rely on bidirectional communications between tumor cells and the associated environment. Several signaling pathways in tumor cells, including Akt, mTOR, STAT3, and Notch, may be responsible for the altered tumor environment exposed to tumor therapies (Figure 5). Surprisingly, tumor cells can adaptively inhibit oncogenic AKT, which induces the secretion of inflammatory molecules such as IL-6/8 and extracellular vehicles (EVs) to restrict the damage induced by therapy (Salony et al., 2016). Thus, suppression of AKT signaling can increase drug resistance in tumor cells (Manning and Cantley, 2007). Moreover, mTOR acts as a vital protein to regulate cell growth both in physiological and pathological conditions (Guri and Hall, 2016). It has been shown that the secretome in the TME can activate mTOR signaling after treatment. Blocking mTOR signaling can restore the sensitivity of several anti-tumor drugs including crizotinib, vemurafenib, and erlotinib (Obenauf et al., 2015). Additionally, the ATM-TRAF6-TAK1 axis related with DNA damage may be involved in these processes (Zhang B. et al., 2018). Surprisingly, some metabolites in the TME, such as the lactate, have been reported to activate the mTOR pathway through glutamine metabolic pathways, inducing the resistance to VEGF inhibitors (Allen et al., 2016).
In addition, the STAT3 pathway can rapidly respond to cytokines, including L-1 $\beta$ and IL- 6 released from neutrophils, TAMs, and CAFs in the TME (Samavati et al., 2009; Kim et al., 2016). Activated STAT3 induces resistance by promoting EMT, increasing anti-apoptotic signaling, and regulating miRNAs and exosomes (Yin et al., 2017; Wang L. et al., 2018). For example, STAT3 can promote the secretion of exosomes by upregulating Rab, which induces platinum resistance in ovarian tumors (Dorayappan et al., 2018). In addition, activated STAT3 can regulate the delivery of drugs by triggering vascular abnormalities (Nagathihalli et al., 2015). Notch is another crucial adaptive signaling pathway responsible for the TME-induced chemotherapy resistance of tumor cells (Meurette and Mehlen, 2018). Exosomes derived from the stroma deliver Jag1, a Notch ligand, activate the Notch pathway to trigger resistance in breast tumor cells (Boelens et al., 2014). CAFs also can release IL-6 to activate the Notch pathway in breast tumor cells (Studebaker et al., 2008). Induction of Notch3 is also relevant to CSCs transformation in liver cancer (Lin et al., 2017). Accordingly, these signaling pathways response to TME may be potential targets from a therapeutic perspective.

\section{TARGETING THE TUMOR MICROENVIRONMENT FOR THERAPY}

Multiple preclinical studies implicate the TME as a potential therapeutic target (Jin and Jin, 2020). For instance, multiple strategies of combined therapy related to the TME have shown interesting potential (Table 1). In the TME, tumor cells usually hijack CAFs, ECM, the immune system, hypoxia, and acidosisrelated pathways to escape immune surveillance. For example, dysregulated immune signaling pathways have been proven to impair several processes including antigen presentation and $\mathrm{T}$ cell infiltration. Thus, targeting the TME might have the potential ability to reverse the resistance of tumor cells.

\section{Targeting Cancer-Associated Fibroblasts}

Given the critical role of CAFs, the most abundant cell type in the TME, in therapeutic resistance of tumor cells, emerging evidence supports targeting protumorigenic CAF functions as a promising approach for tumor therapy (Truffi et al., 2020). For example, conophylline is used to treat refractory pancreatic cancers by suppressing CAF activity and the proliferation and secretion of cytokines (Zhen et al., 2017; Umezawa et al., 2018; Ishii et al., 2019). The cell surface markers GPR77 and CD10, specifically expressed in CAFs, are involved in chemoresistance in lung and breast cancer (Vaquero et al., 2018). Treatment with inhibitors of these molecules is a breakthrough in overcoming resistance. For example, using a GPR77-neutralizing antibody to selectively inhibit CAFs is an effective way to restore the sensitivity of drugs. Another strategy is to inhibit the activation of protumorigenic pathways in CAFs. Inhibition of Hedgehog signaling in CAFs successfully enhances the effect of docetaxel chemotherapy in TNBC patients (Cazet et al., 2018). In addition, reversing activated CAFs into a dormant state is also an effective therapeutic strategy. The VDR is considered to 


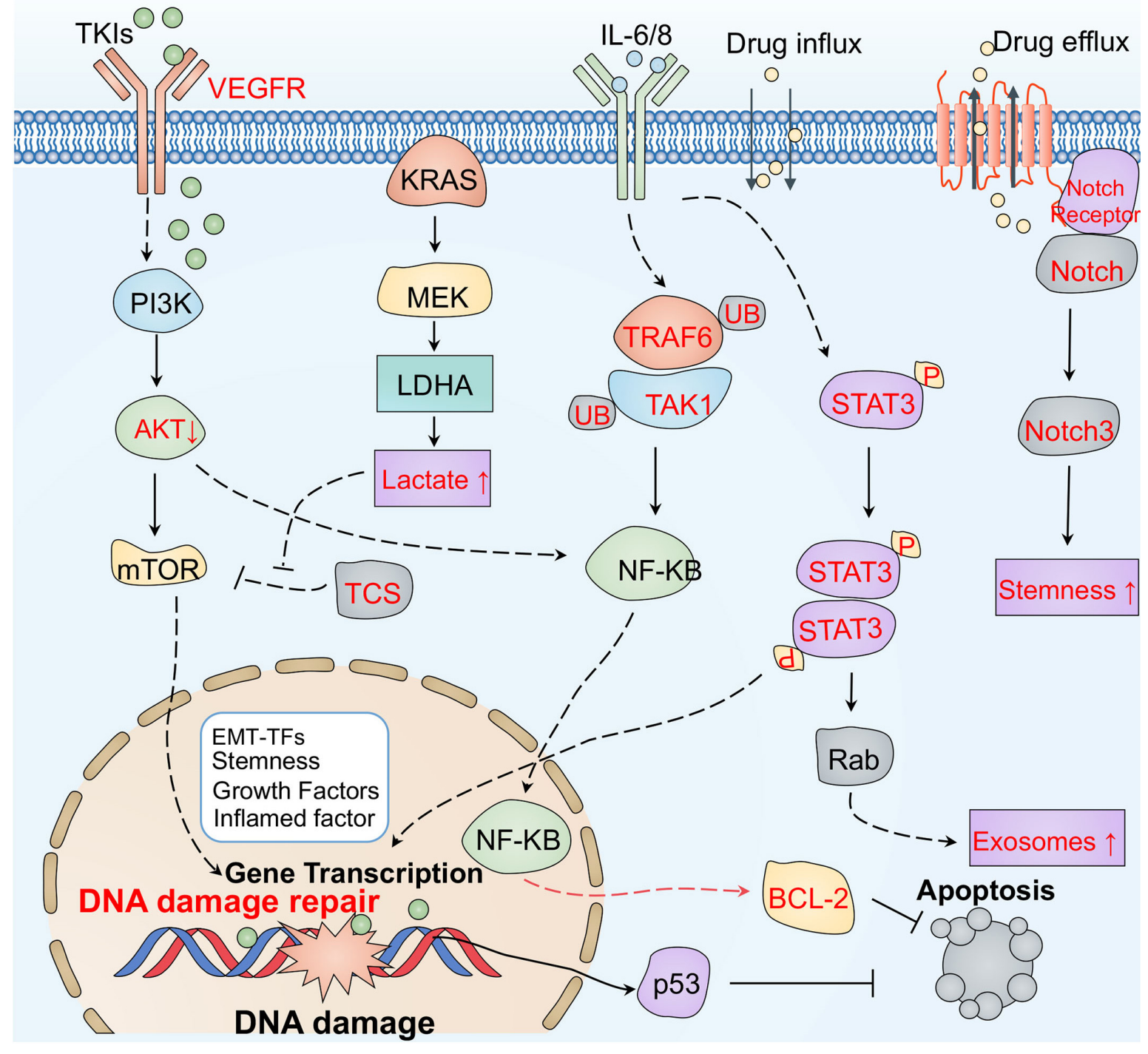

FIGURE $\mathbf{5}$ | The main signaling pathways responsible for therapeutic resistance mediated by the tumor environment. Tumor cells can adaptively inhibit oncogenic AKT, which induces the secretion of inflammatory molecules such as IL-6/8, and EVs to restrict damage during therapy. The ATM-TRAF6-TAK1 axis related with DNA damage may also be involved in resistance. Some metabolites, such as lactate, in the TME have been reported to activate the mTOR pathway through glutamine metabolic pathways, inducing resistance to VEGF inhibitors. In addition, the STAT3 pathway may also rapidly respond to cytokines, promoting the secretion of exosomes, by upregulating Rab and increasing anti-apoptotic signaling in the TME. IL-6 and exosomes derived from the stroma deliver Jag1, Notch ligand, and Notch3 activate the Notch pathway to trigger resistance.

be a targeted molecule that regulates the transcriptional process to activate CAFs in pancreatic cancer (Yamashita et al., 2012). Interestingly, compared with gemcitabine alone, the synergistic effect of gemcitabine and a VDR ligand suppresses fibrosis and inflammation, and restores the sensitivity of gemcitabine by increasing tumor uptake, thereby improving the survival rate to 57\% (Yamashita et al., 2012; Yang et al., 2016). Studies have also found that nanoparticles loaded with a secreted sTRAIL can reduce the activation of CAFs in pancreatic cancers (Yang et al., 2016). Currently, some clinical trials targeting CAFs are being implemented. The agent RO6874281 is an interleukin-2 variant targeting FAP that is being evaluated for its clinical benefit in combination with atezolizumab, gemcitabine, or vinorelbine in the treatment of advanced tumors. The synergistic treatment of RO6874281 with trastuzumab or cetuximab in patients with head and neck cancer or breast tumors is also in clinical trials.

\section{Targeting the Extracellular Matrix}

Blocking the communication between tumor cells and their environment by targeting adhesion molecules, proteolytic enzymes, and ECM components has been demonstrated as an efficient strategy for tumor therapy (Pickup et al., 2014; 
TABLE 1 | Combination therapies against cancer used in recent clinical trials.

\begin{tabular}{|c|c|c|}
\hline $\begin{array}{l}\text { Conventional } \\
\text { drug }\end{array}$ & Combination therapy & Cancer targeted \\
\hline \multirow[t]{3}{*}{ Statin } & $\begin{array}{l}\text { Targeted therapy such } \\
\text { as erlotinib, sorafenib, } \\
\text { fulvestrant, aromatase } \\
\text { inhibitors, anti-HER2 }\end{array}$ & $\begin{array}{c}\text { NSCLC, HCC, } \\
\text { ESCA, and breast } \\
\text { cancer }\end{array}$ \\
\hline & Radiotherapy & GBM \\
\hline & $\begin{array}{l}\text { Chemotherapy such as } \\
\text { topotecan, zoledronate, } \\
\text { bendamustin, and } \\
\text { capecitabine }\end{array}$ & $\begin{array}{c}\text { TNBC, pediatric } \\
\text { solid and CNS } \\
\text { tumor, rectal cancer }\end{array}$ \\
\hline \multirow[t]{3}{*}{ Metformin } & $\begin{array}{l}\text { Targeted therapy such } \\
\text { as lanreotide, } \\
\text { toremifene, trametinib, } \\
\text { gefitinib, and lapatinib }\end{array}$ & $\begin{array}{l}\text { NSCLC, CRC, } \\
\text { TNBC, LAML, } \\
\text { UCEC and } \\
\text { melanoma, kidney } \\
\text { cancer, breast } \\
\text { cancer }\end{array}$ \\
\hline & Radiotherapy & $\begin{array}{l}\text { HNSCC, CESC, } \\
\text { lung cancer }\end{array}$ \\
\hline & $\begin{array}{l}\text { Chemotherapy such as } \\
\text { docetaxel, oxaliplatin, } \\
\text { temozolomide, } \\
\text { gemcitabine, and } \\
\text { paclitaxel }\end{array}$ & $\begin{array}{c}\text { ESCA, PDAC, } \\
\text { GBM, and prostate } \\
\text { cancer, breast } \\
\text { cancer }\end{array}$ \\
\hline \multirow[t]{2}{*}{ Aspirin } & $\begin{array}{l}\text { Targeted therapy such } \\
\text { as osimertinib }\end{array}$ & NSCLC \\
\hline & $\begin{array}{l}\text { Immunotherapy such } \\
\text { as atezolizumab, } \\
\text { avelumab, } \\
\text { bevacizumab, and } \\
\text { ipilimumab }\end{array}$ & $\begin{array}{c}\text { HNSCC, TNBC, } \\
\text { and OV }\end{array}$ \\
\hline \multirow[t]{4}{*}{ Celecoxib } & $\begin{array}{l}\text { Targeted therapy such } \\
\text { as gefitinib, } \\
\text { depsipeptide, } \\
\text { toripalimab }\end{array}$ & $\begin{array}{l}\text { ESCA, CRC, } \\
\text { HNSCC, NSCLC, } \\
\text { OV, and breast } \\
\text { cancer }\end{array}$ \\
\hline & Radiotherapy & NSCLC \\
\hline & $\begin{array}{l}\text { Chemotherapy such as } \\
\text { docetaxel, cisplatin, } \\
\text { paclitaxel, and } \\
\text { methotrexate }\end{array}$ & $\begin{array}{c}\text { NSCLC, GBM, } \\
\text { TNBC, CRC, and } \\
\text { PDAC }\end{array}$ \\
\hline & $\begin{array}{l}\text { Immunotherapy such } \\
\text { as nivolumab }\end{array}$ & NSCLC \\
\hline
\end{tabular}

Hirata and Sahai, 2017). For example, suppression of the integrin-mediated bidirectional transmitting signals between cells and ECM has been used to prevent therapeutic resistance (Kechagia et al., 2019). Blocking the activity of $\beta 1$ integrin with monoclonal antibody AIIB2 can significantly increase the outcome of HER2-targeting agents as well as radiotherapy (Park et al., 2008; Weigelt et al., 2010; Hirata and Sahai, 2017). The antagonist of integrin $\alpha 4 \beta 1$ and $\alpha 4 \beta 7$, natalizumab, has been proven to recover the sensitivity of chemotherapy drugs in malignant tumors, including acute lymphoblastic leukemia (AML) and ovarian tumor (Podar et al., 2011; Hsieh et al., 2013; Scalici et al., 2014; Hirata and Sahai, 2017). Matrix metalloproteinases (MMPs), one of the major ECM components, function as proteases to detach cancer cells out of the ECM, participating in tumor development, metastasis, and resistance (Najafi et al., 2019). Several agents targeting MMPs have been developed for treating advanced carcinomas including incyclinide, JNJ0966 for MMP-9, and the antibody Fab 3369 for MMP-14 (Ling et al., 2017; Scannevin et al., 2017).

TGF- $\beta$ signaling is another pathway which mediates communication between tumor cells and their ECM. Therefore, anti-TGF $\beta$ drugs, including neutralizing antibodies, ligand traps, small-molecule kinase inhibitors, and antisense oligonucleotides (AONs), are a potential strategy for improving therapeutic efficacy. Blocking TGF- $\beta$ by 1 D11, a TGF- $\beta$ neutralizing antibody, can improve the intra-tumoral penetration of both chemotherapeutic drugs and nanotherapeutic agents by normalizing the tumor interstitial matrix, thereby resulting in a better control of tumor growth (Liu et al., 2012). Galunisertib (LY2157299), an oral small-molecule inhibitor of T $\beta$ RI, sensitizes colorectal cancer cells to RTK inhibitors (Brunen et al., 2013; Colak and ten Dijke, 2017). Blockade of TGF- $\beta$ has been found to promote the anti-tumor activity of $\mathrm{CD}^{+} \mathrm{T}$ cells, thereby reversing the resistance to a $\mathrm{PD}-1 / \mathrm{PD}-\mathrm{L} 1$ blockade in the TME (Chen et al., 2018). Moreover, TGF- $\beta$ blockade by expressing dominant-negative TGF- $\beta$ receptor II enhances the efficacy of TCR gene therapy against advanced cancers (Bendle et al., 2013). Both fresolimumab, a pan-TGF- $\beta$ neutralizing antibody, and LY3022859, an anti-T $\beta$ RII IgG1 monoclonal antibody, exhibited anti-tumor activity in a phase 1 clinical trial for various cancers (Colak and ten Dijke, 2017). T $\beta R$ inhibitors, including LY2157299 and PF06952229, have being tested in clinical trials for patients with advanced or drug-resistant cancers (NCT03685591) (Liu et al., 2021).

However, some studies suggest that targeting the ECM has limited outcomes in advanced malignancies such as GBM, melanoma, and prostate tumors, suggesting that different tumors with different extracellular matrices can exhibit different results (Eisele et al., 2014; Stupp et al., 2014; Hirata and Sahai, 2017). Therefore, further investigation and clinical trials are necessary to ensure treatment using ECM-targeting strategies are effective and safe.

\section{Targeting the Immune System}

As mentioned above, the immune system in TME dramatically affects the response of tumors to various treatment approaches. Therefore, multiple strategies based on targeting the immune system have been used to tackle cancers: (i) inhibiting the recruitment of macrophages to tumor tissues; (ii) blocking the differentiation of macrophages toward TAMs; (iii) enhancing the anti-tumor activity of the immune system (Joyce, 2005; Tsai et al., 2014; Roma-Rodrigues et al., 2019). Several studies indicate that combination treatment using conventional therapies and immunotherapy achieves satisfactory clinical outcomes. Indeed, the combination of chemotherapy drugs and immune checkpoint inhibitors (ICIs) has shown a better result compared with chemotherapy alone (Ridker et al., 2017; Tulotta and Ottewell, 2018). Consistently, targeting CTLs with pembrolizumab enhances the clinical efficacy of cisplatin in drug-resistant patients (Ridker et al., 2017). These promising results have prompted a series of clinical studies to validate this combination therapy strategy. The suppression of MDSCs by anti-CSF-1R neutralizing antibodies or small molecule inhibitors 
has been shown to reduce tumor growth and metastasis (Noy and Pollard, 2014; Szebeni et al., 2016; Ridker et al., 2017). Immune checkpoint molecules in NKs were also reported to be potential targets for immunotherapy (Cao et al., 2020). To date approximately 174 clinical trials involving CTLA-4 and 750 involving PD-1 and its receptor PD-L1 have been reported (as reviewed in Boohaker et al., 2018; Darvin et al., 2018; Chen T. et al., 2019). A combination with blocking antibodies against CTLA-4 and PD-1 results in significantly higher response rates and improved survival in patients with metastatic melanoma (Wolchok et al., 2013; Horvat et al., 2015; Larkin et al., 2015; Robert et al., 2015). Moreover, Kineret, an IL1 receptor antagonist that is often used for rheumatoid arthritis, has exhibited promising results for breast cancer patients (Tulotta and Ottewell, 2018). The anti-IL-1 antibody canakinumab, which is often used for inflammatory diseases, has shown improved clinical outcomes in lung cancer (Ridker et al., 2017). More recently, canakinumab has been proposed for the treatment of highly aggressive tumors NSCLC and triple negative breast cancer (Houriet et al., 2017; Dhorepatil et al., 2019; Paz-Ares et al., 2019; Schenk et al., 2019; Sehested et al., 2019). In addition, combining traditional therapies with immune therapies has shown potential to reverse resistance (Patel and Minn, 2018; Gomez et al., 2020). For example, the combination of HMTs with immune therapy has shown efficacy for various cancer in preclinical studies (Zingg et al., 2017; Patel and Minn, 2018; Gomez et al., 2020). Treatment with EZH2 inhibitor and antibodies blocking CTLA-4 was reported to reverse immunosuppressive effects and significantly improve survival in preclinical models (Zingg et al., 2017). Moreover, DNMTi or HDACi treatment was reported to sensitize resistant cancer cells in mouse models of melanoma and lung adenocarcinoma (Chiappinelli et al., 2016; Strick et al., 2016; Zheng et al., 2016; Stone et al., 2017). The combination of HDACis, DNMTis, anti-CTLA4, and anti-PD1 together showed significantly improved rates of survival, with $75 \%$ of mice with tumors being cured (Kim et al., 2014; Zheng et al., 2016). Thus, targeting the immune system, especially in combination with traditional chemotherapy to promote survival and reverse resistance, may prove to be a safe and effective strategy for multiple types of tumors, benefitting more patients.

\section{Targeting Hypoxia and Acidosis}

As mentioned above, low oxygen pressure and acidosis conditions in the TME dramatically affect a tumor's response to treatment. Therefore, it is rational to manipulate hypoxia and acidosis conditions in the TME to hinder tumor progression (Paolicchi et al., 2016; Roma-Rodrigues et al., 2019). Accordingly, topotecan, an inhibitor of HIF-1 $\alpha$, has been used to cure advanced tumors including ovarian and small cell lung cancers (Roma-Rodrigues et al., 2019). Topotecan has also been used in a clinical study for the treatment of refractory advanced solid neoplasms expressing HIF-1 $\alpha$. Additionally, several clinical trials based on intervention against hypoxia are underway, including the evaluation of everolimus, which downregulates HIF-1 $\alpha$, in combination with lenvatinib in renal cancer (NCT01206764), as well as an evaluation of the metformin outcomes in tissue oxygenation of head and neck cancer (NCT03510390) (RomaRodrigues et al., 2019). The acidified environment has been considered to protect tumor cells from chemotherapy by affecting the concentration of drugs (Kolosenko et al., 2017). Hence, recent clinical trials have focused on alteration of the acidification environment by targeting carbonic anhydrases, a family of enzymes that regulate the $\mathrm{pH}$ of active cells/tissues in tumors (Supuran, 2018). For example, the synergistic treatment of acetazolamide, a carbonic anhydrase inhibitor, with radiotherapy has been tested in lung cancer (NCT03467360) while the combination of acetazolamide and temozolomide has also been trialed for brain cancer (NCT03011671).

\section{DISCUSSION}

In this review, we have summarized the current insights into how the TME regulates cancer resistance to therapies. The adaptive resistance to cancer treatment driven by the TME may play a vital role in tumor recurrence and metastasis. Therefore, a variety of approaches targeting the TME have been developed to reverse resistance to radiotherapy, chemotherapy, and immunotherapy (Xu et al., 2015; Zhang et al., 2015; Hu et al., 2017; Tan et al., 2018; Bhat et al., 2021). Hijacking the TME to increase drug delivery has also been demonstrated to enhance the efficacy of chemotherapeutic drugs (Fang et al., 2018; Amini et al., 2019). Although a large number of studies have shown the successful application of manipulating the TME to overcome resistance, there are several key questions that still need to be resolved. Firstly, the mechanisms underlying adaptive and non-adaptive resistance need further investigation in a real TME. To date, most of the studies have been based on resistant cells in vitro, which excludes the factors in the TME that may be vital for acquired resistance in vivo. Co-culture of tumor cells with other types of cells within the TME and tumor-microenvironment-on-a-chip (TMOC) models can only partially mimic the real TME. More studies should be conducted using appropriate mouse models, or the use of human organoids isolated from patient biopsies, to fully understand the role of TME adaptive and non-adaptive resistance (Papapetrou, 2016; Mazzarella and Curigliano, 2018; Vlachogiannis et al., 2018). Secondly, since the TME changes dynamically during the development and treatment of tumors, understanding and monitoring the factors that influence the therapeutic effects of targeting the TME is necessary to improve patient safety and survival outcome. Lastly, some drawbacks of targeting the TME, such as immune-related side-effects, may lead to the cessation of treatment (Liu et al., 2017; García-Aranda and Redondo, 2019). Hopefully, as our understating of intrinsic biology of the TME is improved, we will be more capable of preempting or reversing cancer therapy resistance.

\section{AUTHOR CONTRIBUTIONS}

NX, JL, and PW conceptualized the manuscript. PW and WG collected the literature and wrote the manuscript. MS and WZ made the figures. EN made significant revisions to the manuscript. All authors read and approved the final manuscript. 


\section{FUNDING}

This work was supported by grants from the National Natural Science Foundation of China (81821002, 81790251, 81972665, and 81960423), the National Key Research and Development Project (2020YFA0509400 and 2020YFC2002705), the Guangdong Basic and Applied Basic Research Foundation (2019B030302012), and the Potential Postdoctoral

\section{REFERENCES}

Acosta, J. C., Banito, A., Wuestefeld, T., Georgilis, A., Janich, P., Morton, J. P., et al. (2013). A complex secretory program orchestrated by the inflammasome controls paracrine senescence. Nat. Cell Biol. 15, 978-990. doi: 10.1038/ ncb2784

Ahmed, K. M., Zhang, H., and Park, C. C. (2013). NF-кB regulates radioresistance mediated By $\beta 1$-Integrin in three-dimensional culture of breast cancer cells. Cancer Res. 73, 3737-3748. doi: 10.1158/0008-5472.Can-12-3537

Allen, E., Miéville, P., Warren, C. M., Saghafinia, S., Li, L., Peng, M. W., et al. (2016). Metabolic symbiosis enables adaptive resistance to anti-angiogenic therapy that is dependent on mTOR signaling. Cell Rep. 15, 1144-1160. doi: 10.1016/j.celrep. 2016.04.029

Amini, M. A., Abbasi, A. Z., Cai, P., Lip, H., Gordijo, C. R., Li, J., et al. (2019). Combining tumor microenvironment modulating nanoparticles with doxorubicin to enhance chemotherapeutic efficacy and boost antitumor immunity. J. Natl. Cancer Inst. 111, 399-408. doi: 10.1093/jnci/djy131

Angelin, A., Gil-de-Gómez, L., Dahiya, S., Jiao, J., Guo, L., Levine, M. H., et al. (2017). Foxp3 reprograms T Cell metabolism to function in low-glucose, highlactate environments. Cell Metab. 25, 1282.e7-1293.e7. doi: 10.1016/j.cmet. 2016.12.018

Antognelli, C., Moretti, S., Frosini, R., Puxeddu, E., Sidoni, A., and Talesa, V. N. (2019). Methylglyoxal acts as a tumor-promoting factor in anaplastic thyroid cancer. Cells 8:547. doi: 10.3390/cells8060547

Antognelli, C., and Talesa, V. N. (2018). Glyoxalases in urological malignancies. Int. J. Mol. Sci. 19:415. doi: 10.3390/ijms19020415

Apicella, M., Giannoni, E., Fiore, S., Ferrari, K. J., Fernández-Pérez, D., Isella, C., et al. (2018). Increased lactate secretion by cancer cells sustains non-cellautonomous adaptive resistance to MET and EGFR targeted therapies. Cell Metab. 28, 848.e6-865.e6. doi: 10.1016/j.cmet.2018.08.006

Ariotti, C., Wagner, V. P., Salvadori, G., Carrard, V. C., Martins, M. A. T., da Cunha Filho, J. J., et al. (2015). VEGFR1 and VEGFR2 in lip carcinogenesis and its association with microvessel density. Tumor Biol. 36, 7285-7292.

Arneth, B. (2019). Tumor microenvironment. Medicina 56:15. doi: 10.3390/ medicina56010015

Assaraf, Y. G., Brozovic, A., Gonçalves, A. C., Jurkovicova, D., Linē, A., Machuqueiro, M., et al. (2019). The multi-factorial nature of clinical multidrug resistance in cancer. Drug Resistance Updates 46:100645. doi: 10.1016/j.drup. 2019.100645

Aung, T., Chapuy, B., Vogel, D., Wenzel, D., Oppermann, M., Lahmann, M., et al. (2011). Exosomal evasion of humoral immunotherapy in aggressive B-cell lymphoma modulated by ATP-binding cassette transporter A3. Proc. Natl. Acad. Sci. U.S.A. 108, 15336-15341.

Aydin, E., Johansson, J., Nazir, F. H., Hellstrand, K., and Martner, A. (2017). Role of NOX2-derived reactive oxygen species in NK cell-mediated control of murine melanoma metastasis. Cancer Immunol. Res. 5, 804-811. doi: 10.1158/23266066.Cir-16-0382

Balkwill, F. R., Capasso, M., and Hagemann, T. (2012). The tumor microenvironment at a glance. J. Cell Sci. 125(Pt 23), 5591-5596. doi: $10.1242 /$ jcs. 116392

Barnes, E. M. E., Xu, Y., Benito, A., Herendi, L., Siskos, A. P., Aboagye, E. O., et al. (2020). Lactic acidosis induces resistance to the pan-Akt inhibitor uprosertib in colon cancer cells. Br. J. Cancer 122, 1298-1308. doi: 10.1038/s41416-0200777-y

Baumann, T., Dunkel, A., Schmid, C., Schmitt, S., Hiltensperger, M., Lohr, K., et al. (2020). Regulatory myeloid cells paralyze T cells through cell-cell transfer of
Program of Chengdu University of Traditional Chinese Medicine (BSH2019019).

\section{ACKNOWLEDGMENTS}

We thank the collaborators for their contributions to the publications cited in this review article.

the metabolite methylglyoxal. Nat. Immunol. 21, 555-566. doi: 10.1038/s41590020-0666-9

Belli, C., Trapani, D., Viale, G., D’Amico, P., Duso, B. A., Della Vigna, P., et al. (2018). Targeting the microenvironment in solid tumors. Cancer Treat. Rev. 65, 22-32. doi: 10.1016/j.ctrv.2018.02.004

Bendle, G. M., Linnemann, C., Bies, L., Song, J. Y., and Schumacher, T. N. (2013). Blockade of TGF- $\beta$ signaling greatly enhances the efficacy of TCR gene therapy of cancer. J. Immunol. 191, 3232-3239. doi: 10.4049/jimmunol.13 01270

Benjamin, L. E., Golijanin, D., Itin, A., Pode, D., and Keshet, E. (1999). Selective ablation of immature blood vessels in established human tumors follows vascular endothelial growth factor withdrawal. J. Clin. Invest. 103, 159-165.

Bhat, A. A., Yousuf, P., Wani, N. A., Rizwan, A., Chauhan, S. S., Siddiqi, M. A., et al. (2021). Tumor microenvironment: an evil nexus promoting aggressive head and neck squamous cell carcinoma and avenue for targeted therapy. Signal Transduct. Target. Ther. 6:12. doi: 10.1038/s41392-020-00419-w

Billottet, C., Tuefferd, M., Gentien, D., Rapinat, A., Thiery, J. P., Broët, P., et al. (2008). Modulation of several waves of gene expression during FGF-1 induced epithelial-mesenchymal transition of carcinoma cells. J. Cell Biochem. 104, 826-839. doi: 10.1002/jcb.21667

Boelens, M. C., Wu, T. J., Nabet, B. Y., Xu, B., Qiu, Y., Yoon, T., et al. (2014). Exosome transfer from stromal to breast cancer cells regulates therapy resistance pathways. Cell 159, 499-513.

Boohaker, R. J., Sambandam, V., Segura, I., Miller, J., Suto, M., and Xu, B. (2018). Rational design and development of a peptide inhibitor for the PD-1/PD-L1 interaction. Cancer Lett. 434, 11-21. doi: 10.1016/j.canlet.2018.04.031

Brand, A., Singer, K., Koehl, G. E., Kolitzus, M., Schoenhammer, G., Thiel, A., et al. (2016). LDHA-associated lactic acid production blunts tumor immunosurveillance by T and NK cells. Cell Metab. 24, 657-671. doi: 10.1016/ j.cmet.2016.08.011

Brown, J. M., and Wilson, W. R. (2004). Exploiting tumour hypoxia in cancer treatment. Nat. Rev. Cancer 4, 437-447. doi: 10.1038/nrc1367

Brunen, D., Willems, S., Kellner, U., Midgley, R., Simon, I., and Bernards, R. (2013). TGF- $\beta$ : an emerging player in drug resistance. Cell Cycle 12, 2960-2968. doi: $10.4161 /$ cc. 26034

Bussink, J., Kaanders, J. H., and van der Kogel, A. J. (2003). Tumor hypoxia at the micro-regional level: clinical relevance and predictive value of exogenous and endogenous hypoxic cell markers. Radiother. Oncol. 67, 3-15.

Calvo, F., Ege, N., Grande-Garcia, A., Hooper, S., Jenkins, R. P., Chaudhry, S. I., et al. (2013). Mechanotransduction and YAP-dependent matrix remodelling is required for the generation and maintenance of cancer-associated fibroblasts. Nat. Cell Biol. 15, 637-646. doi: 10.1038/ncb2756

Cao, Q., Cai, W., Li, T., Yang, Y., Chen, K., Xing, L., et al. (2006). Combination of integrin siRNA and irradiation for breast cancer therapy. Biochem. Biophys. Res. Commun. 351, 726-732. doi: 10.1016/j.bbrc.2006.10.100

Cao, Y., Wang, X., Jin, T., Tian, Y., Dai, C., Widarma, C., et al. (2020). Immune checkpoint molecules in natural killer cells as potential targets for cancer immunotherapy. Signal Transduct. Target. Ther. 5:250. doi: 10.1038/s41392020-00348-8

Carmeliet, P., and Jain, R. K. (2000). Angiogenesis in cancer and other diseases. Nature 407, 249-257. doi: 10.1038/35025220

Cassim, S., and Pouyssegur, J. (2019). Tumor microenvironment: a metabolic player that shapes the immune response. Int. J. Mol. Sci. 21:157. doi: 10.3390/ ijms21010157

Cazet, A. S., Hui, M. N., Elsworth, B. L., Wu, S. Z., Roden, D., Chan, C. L., et al. (2018). Targeting stromal remodeling and cancer stem cell plasticity overcomes 
chemoresistance in triple negative breast cancer. Nat. Commun. 9:2897. doi: 10.1038/s41467-018-05220-6

Cervantes-Villagrana, R. D., Albores-García, D., Cervantes-Villagrana, A. R., and García-Acevez, S. J. (2020). Tumor-induced neurogenesis and immune evasion as targets of innovative anti-cancer therapies. Signal Transduct. Target. Ther. 5:99. doi: 10.1038/s41392-020-0205-Z

Chakravarthy, A., Khan, L., Bensler, N. P., Bose, P., and De Carvalho, D. D. (2018). TGF- $\beta$-associated extracellular matrix genes link cancer-associated fibroblasts to immune evasion and immunotherapy failure. Nat. Commun. 9, 1-10.

Chan, T. S., Hsu, C. C., Pai, V. C., Liao, W. Y., Huang, S. S., Tan, K. T., et al. (2016). Metronomic chemotherapy prevents therapy-induced stromal activation and induction of tumor-initiating cells. J. Exp. Med. 213, 2967-2988. doi: 10.1084/ jem. 20151665

Chang, C. H., Qiu, J., O'Sullivan, D., Buck, M. D., Noguchi, T., Curtis, J. D., et al. (2015). Metabolic competition in the tumor microenvironment is a driver of cancer progression. Cell 162, 1229-1241. doi: 10.1016/j.cell.2015.08.016

Che, Y., Wang, J., Li, Y., Lu, Z., Huang, J., Sun, S., et al. (2018). Cisplatinactivated PAI-1 secretion in the cancer-associated fibroblasts with paracrine effects promoting esophageal squamous cell carcinoma progression and causing chemoresistance. Cell Death Dis. 9, 1-13.

Chen, F., Zhuang, X., Lin, L., Yu, P., Wang, Y., Shi, Y., et al. (2015). New horizons in tumor microenvironment biology: challenges and opportunities. BMC Med. 13:45. doi: 10.1186/s12916-015-0278-7

Chen, W. L., Wang, C. C., Lin, Y. J., Wu, C. P., and Hsieh, C. H. (2015). Cycling hypoxia induces chemoresistance through the activation of reactive oxygen species-mediated B-cell lymphoma extra-long pathway in glioblastoma multiforme. J. Transl. Med. 13:389. doi: 10.1186/s12967-015-0758-8

Chen, S., and Sang, N. (2016). Hypoxia-inducible factor-1: a critical player in the survival strategy of stressed cells. J. Cell Biochem. 117, 267-278. doi: 10.1002/ jcb. 25283

Chen, S.-H., and Chang, J.-Y. (2019). New insights into mechanisms of cisplatin resistance: from tumor cell to microenvironment. Int. J. Mol. Sci. 20:4136. doi: $10.3390 /$ ijms 20174136

Chen, T., Li, Q., Liu, Z., Chen, Y., Feng, F., and Sun, H. (2019). Peptide-based and small synthetic molecule inhibitors on PD-1/PD-L1 pathway: a new choice for immunotherapy? Eur. J. Med. Chem. 161, 378-398. doi: 10.1016/j.ejmech.2018. 10.044

Chen, Y., Liu, X., Yuan, H., Yang, Z., von Roemeling, C. A., Qie, Y., et al. (2019). Therapeutic remodeling of the tumor microenvironment enhances nanoparticle delivery. Adv. Sci. 6:1802070.

Chen, X., Wang, L., Li, P., Song, M., Qin, G., Gao, Q., et al. (2018). Dual TGF- $\beta$ and PD-1 blockade synergistically enhances MAGE-A3-specific CD8(+) T cell response in esophageal squamous cell carcinoma. Int. J. Cancer 143, 2561-2574. doi: $10.1002 /$ ijc. 31730

Cheng, P., Levesque, M. P., Dummer, R., and Mangana, J. (2020). Targeting complex, adaptive responses in melanoma therapy. Cancer Treatm. Rev. 86:101997. doi: 10.1016/j.ctrv.2020.101997

Cheteh, E. H., Augsten, M., Rundqvist, H., Bianchi, J., Sarne, V., Egevad, L., et al. (2017). Human cancer-associated fibroblasts enhance glutathione levels and antagonize drug-induced prostate cancer cell death. Cell Death Dis. 8:e2848. doi: $10.1038 /$ cddis. 2017.225

Chiappinelli, K. B., Zahnow, C. A., Ahuja, N., and Baylin, S. B. (2016). Combining epigenetic and immunotherapy to combat cancer. Cancer Res. 76, 1683-1689. doi: 10.1158/0008-5472.Can-15-2125

Colak, S., and ten Dijke, P. (2017). Targeting TGF- $\beta$ signaling in cancer. Trends Cancer 3, 56-71.

Corcoran, C., Rani, S., O’Brien, K., O’Neill, A., Prencipe, M., Sheikh, R., et al. (2012). Docetaxel-resistance in prostate cancer: evaluating associated phenotypic changes and potential for resistance transfer via exosomes. PLoS One 7:e50999. doi: 10.1371/journal.pone.0050999

Corrado, C., Raimondo, S., Chiesi, A., Ciccia, F., De Leo, G., and Alessandro, R. (2013). Exosomes as intercellular signaling organelles involved in health and disease: basic science and clinical applications. Int. J. Mol. Sci. 14, 5338-5366. doi: $10.3390 / \mathrm{ijms} 14035338$

Correia, A. L., and Bissell, M. J. (2012). The tumor microenvironment is a dominant force in multidrug resistance. Drug Resist. Updat 15, 39-49. doi: 10.1016/j.drup.2012.01.006
Cowan, D. S., and Tannock, I. F. (2001). Factors that influence the penetration of methotrexate through solid tissue. Int. J. Cancer 91, $120-125$.

Crow, J., Atay, S., Banskota, S., Artale, B., Schmitt, S., and Godwin, A. K. (2017). Exosomes as mediators of platinum resistance in ovarian cancer. Oncotarget 8:11917.

Cruz da Silva, E., Dontenwill, M., Choulier, L., and Lehmann, M. (2019). Role of integrins in resistance to therapies targeting growth factor receptors in cancer. Cancers 11:692.

Dai, J., Su, Y., Zhong, S., Cong, L., Liu, B., Yang, J., et al. (2020). Exosomes: key players in cancer and potential therapeutic strategy. Signal Transduct. Target. Ther. 5:145. doi: 10.1038/s41392-020-00261-0

Dang, C. V., and Semenza, G. L. (1999). Oncogenic alterations of metabolism. Trends Biochem. Sci. 24, 68-72.

Darvin, P., Toor, S. M., Sasidharan Nair, V., and Elkord, E. (2018). Immune checkpoint inhibitors: recent progress and potential biomarkers. Exp. Mol. Med. 50, 1-11. doi: 10.1038/s12276-018-0191-1

Dauer, P., Zhao, X., Gupta, V. K., Sharma, N., Kesh, K., Gnamlin, P., et al. (2018). Inactivation of cancer-associated-fibroblasts disrupts oncogenic signaling in pancreatic cancer cells and promotes its regression. Cancer Res. 78, 1321-1333. doi: 10.1158/0008-5472.Can-17-2320

Denkert, C., Loibl, S., Noske, A., Roller, M., Muller, B., Komor, M., et al. (2010). Tumor-associated lymphocytes as an independent predictor of response to neoadjuvant chemotherapy in breast cancer. J. Clin. Oncol. 28, $105-113$.

DeRita, R. M., Sayeed, A., Garcia, V., Krishn, S. R., Shields, C. D., Sarker, S., et al. (2019). Tumor-derived extracellular vesicles require \&\#x3b2;1 integrins to promote anchorage-independent growth. iScience 14, 199-209. doi: 10.1016/ j.isci.2019.03.022

Dhorepatil, A., Ball, S., Ghosh, R. K., Kondapaneni, M., and Lavie, C. J. (2019). Canakinumab: promises and future in cardiometabolic diseases and malignancy. Am. J. Med. 132, 312-324.

Díaz-Valdés, N., Basagoiti, M., Dotor, J., Aranda, F., Monreal, I., Riezu-Boj, J. I., et al. (2011). Induction of monocyte chemoattractant protein-1 and interleukin-10 by TGFbetal in melanoma enhances tumor infiltration and immunosuppression. Cancer Res. 71, 812-821. doi: 10.1158/0008-5472.Can10-2698

Dorayappan, K. D. P., Wanner, R., Wallbillich, J. J., Saini, U., Zingarelli, R., Suarez, A. A., et al. (2018). Hypoxia-induced exosomes contribute to a more aggressive and chemoresistant ovarian cancer phenotype: a novel mechanism linking STAT3/Rab proteins. Oncogene 37, 3806-3821. doi: 10.1038/s41388-018-01890

Du, B., and Shim, J. S. (2016). Targeting epithelial-mesenchymal transition (EMT) to overcome drug resistance in cancer. Molecules 21:965. doi: 10.3390/ molecules 21070965

Durand, R. E. (2001). Intermittent blood flow in solid tumours-an underappreciated source of 'drug resistance'. Cancer Metastasis Rev. 20, 57-61.

Eisele, G., Wick, A., Eisele, A.-C., Clément, P. M., Tonn, J., Tabatabai, G., et al. (2014). Cilengitide treatment of newly diagnosed glioblastoma patients does not alter patterns of progression. J. Neuro Oncol. 117, 141-145. doi: 10.1007/ s11060-014-1365-x

Eke, I., and Cordes, N. (2015). Focal adhesion signaling and therapy resistance in cancer. Semin. Cancer Biol. 31, 65-75. doi: 10.1016/j.semcancer.2014.07.009

Fang, J., Zhang, S., Xue, X., Zhu, X., Song, S., Wang, B., et al. (2018). Quercetin and doxorubicin co-delivery using mesoporous silica nanoparticles enhance the efficacy of gastric carcinoma chemotherapy. Int. J. Nanomed. 13, 5113-5126. doi: $10.2147 /$ ijn.S170862

Feichtinger, R. G., and Lang, R. (2019). Targeting L-Lactate metabolism to overcome resistance to immune therapy of melanoma and other tumor entities. J. Oncol. 2019:2084195. doi: 10.1155/2019/2084195

Ferlay, J., Colombet, M., Soerjomataram, I., Mathers, C., Parkin, D. M., Piñeros, M., et al. (2019). Estimating the global cancer incidence and mortality in 2018: GLOBOCAN sources and methods. Int. J. Cancer 144, 1941-1953. doi: 10.1002/ ijc.31937

Fiori, M. E., Di Franco, S., Villanova, L., Bianca, P., Stassi, G., and De Maria, R. (2019). Cancer-associated fibroblasts as abettors of tumor progression at the crossroads of EMT and therapy resistance. Mol. Cancer 18:70. doi: 10.1186/ s12943-019-0994-2 
Fiori, M. E., Villanova, L., and De Maria, R. (2017). Cancer stem cells: at the forefront of personalized medicine and immunotherapy. Curr. Opin. Pharmacol. 35, 1-11. doi: 10.1016/j.coph.2017.04.006

Flaherty, K. T., Manola, J. B., Pins, M., McDermott, D. F., Atkins, M. B., Dutcher, J. J., et al. (2015). BEST: a randomized phase II study of vascular endothelial growth factor, RAF kinase, and mammalian target of rapamycin combination targeted therapy with bevacizumab, sorafenib, and temsirolimus in advanced renal cell carcinoma-A trial of the ECOG-ACRIN Cancer Research Group (E2804). J. Clin. Oncol. 33:2384.

Fletcher, M., Ramirez, M. E., Sierra, R. A., Raber, P., Thevenot, P., Al-Khami, A. A., et al. (2015). l-Arginine depletion blunts antitumor T-cell responses by inducing myeloid-derived suppressor cells. Cancer Res. 75, 275-283. doi: 10.1158/0008-5472.Can-14-1491

Freund, A., Orjalo, A. V., Desprez, P. Y., and Campisi, J. (2010). Inflammatory networks during cellular senescence: causes and consequences. Trends Mol. Med. 16, 238-246. doi: 10.1016/j.molmed.2010.03.003

Fu, H., Yang, H., Zhang, X., and Xu, W. (2016). The emerging roles of exosomes in tumor-stroma interaction. J. Cancer Res. Clin. Oncol. 142, 1897-1907. doi: 10.1007/s00432-016-2145-0

Fujita, M., Sasada, M., Iyoda, T., and Fukai, F. (2020). Involvement of integrinactivating peptides derived from tenascin-c in cancer aggression and new anticancer strategy using the fibronectin-derived integrin-inactivating peptide. Molecules 25:3239. doi: 10.3390/molecules25143239

Gabrilovich, D. I., Ostrand-Rosenberg, S., and Bronte, V. (2012). Coordinated regulation of myeloid cells by tumours. Nat. Rev. Immunol. 12, 253-268. doi: $10.1038 /$ nri3175

Galmarini, F. C., Galmarini, C. M., Sarchi, M. I., Abulafia, J., and Galmarini, D. (2000). Heterogeneous distribution of tumor blood supply affects the response to chemotherapy in patients with head and neck cancer. Microcirculation 7, 405-410.

Gamradt, P., De La Fouchardière, C., and Hennino, A. (2021). Stromal proteinmediated immune regulation in digestive cancers. Cancers 13:146. doi: 10.3390/ cancers 13010146

Gandhi, L., Rodríguez-Abreu, D., Gadgeel, S., Esteban, E., Felip, E., De Angelis, F., et al. (2018). Pembrolizumab plus chemotherapy in metastatic non-small-cell lung cancer. N. Engl. J. Med. 378, 2078-2092.

García-Aranda, M., and Redondo, M. (2019). Immunotherapy: a challenge of breast cancer treatment. Cancers 11:1822.

García-Cañaveras, J. C., Chen, L., and Rabinowitz, J. D. (2019). The tumor metabolic microenvironment: lessons from lactate. Cancer Res. 79, 3155-3162. doi: 10.1158/0008-5472.Can-18-3726

Gargiulo, E., Paggetti, J., and Moussay, E. (2019). Hematological malignancyderived small extracellular vesicles and tumor microenvironment: the art of turning foes into friends. Cells 8:511.

Gerweck, L. E., Vijayappa, S., and Kozin, S. (2006). Tumor pH controls the in vivo efficacy of weak acid and base chemotherapeutics. Mol. Cancer Ther. 5, 1275-1279. doi: 10.1158/1535-7163.Mct-06-0024

Gillies, R. J., Schomack, P. A., Secomb, T. W., and Raghunand, N. (1999). Causes and effects of heterogeneous perfusion in tumors. Neoplasia 1, 197-207.

Goel, H. L., Sayeed, A., Breen, M., Zarif, M. J., Garlick, D. S., Leav, I., et al. (2013). $\beta 1$ integrins mediate resistance to ionizing radiation in vivo by inhibiting c-Jun amino terminal kinase 1. J. Cell. Physiol. 228, 1601-1609. doi: 10.1002/jcp.24323

Gomez, S., Tabernacki, T., Kobyra, J., Roberts, P., and Chiappinelli, K. B. (2020). Combining epigenetic and immune therapy to overcome cancer resistance. Semin. Cancer Biol. 65, 99-113. doi: 10.1016/j.semcancer.2019.12.019

Gordon-Weeks, A., and Yuzhalin, A. E. (2020). Cancer extracellular matrix proteins regulate tumour immunity. Cancers 12:3331. doi: 10.3390/cancers12 113331

Gray, M. D., Mann, M., Nitiss, J. L., and Hendershot, L. M. (2005). Activation of the unfolded protein response is necessary and sufficient for reducing topoisomerase IIalpha protein levels and decreasing sensitivity to topoisomerase-targeted drugs. Mol. Pharmacol. 68, 1699-1707. doi: 10.1124/ mol.105.014753

Grivennikov, S. I., Greten, F. R., and Karin, M. (2010). Immunity, inflammation, and cancer. Cell 140, 883-899. doi: 10.1016/j.cell.2010.01.025

Guillaumond, F., Bidaut, G., Ouaissi, M., Servais, S., Gouirand, V., Olivares, O., et al. (2015). Cholesterol uptake disruption, in association with chemotherapy, is a promising combined metabolic therapy for pancreatic adenocarcinoma. Proc. Natl. Acad. Sci. U.S.A. 112, 2473-2478. doi: 10.1073/pnas.142160 1112

Guri, Y., and Hall, M. N. (2016). mTOR signaling confers resistance to targeted cancer drugs. Trends Cancer 2, 688-697. doi: 10.1016/j.trecan.2016. 10.006

Halama, N., Michel, S., Kloor, M., Zoernig, I., Benner, A., Spille, A., et al. (2011). Localization and density of immune cells in the invasive margin of human colorectal cancer liver metastases are prognostic for response to chemotherapy. Cancer Res. 71, 5670-5677.

Hanahan, D. (2014). Rethinking the war on cancer. Lancet 383, 558-563. doi: 10.1016/s0140-6736(13)62226-6

Hanahan, D., and Coussens, L. M. (2012). Accessories to the crime: functions of cells recruited to the tumor microenvironment. Cancer Cell 21, 309-322. doi: 10.1016/j.ccr.2012.02.022

Hanahan, D., and Weinberg, R. A. (2011). Hallmarks of cancer: the next generation. Cell 144, 646-674. doi: 10.1016/j.cell.2011.02.013

Hashizume, H., Baluk, P., Morikawa, S., McLean, J. W., Thurston, G., Roberge, S., et al. (2000). Openings between defective endothelial cells explain tumor vessel leakiness. Am. J. Pathol. 156, 1363-1380.

He, J.-M., Wang, F.-C., Qi, H.-B., Li, Y., and Liang, H.-J. (2009). ). Downregulation of $\alpha \mathrm{v}$ integrin by retroviral delivery of small interfering RNA reduces multicellular resistance of HT29. Cancer Lett. 284, 182-188. doi: 10.1016/j. canlet.2009.04.023

Hegde, P. S., Jubb, A. M., Chen, D., Li, N. F., Meng, Y. G., Bernaards, C., et al. (2013). Predictive impact of circulating vascular endothelial growth factor in four phase III trials evaluating bevacizumab. Clin. Cancer Res. 19, 929-937.

Heldin, C.-H., Rubin, K., Pietras, K., and Östman, A. (2004). High interstitial fluid pressure-an obstacle in cancer therapy. Nat. Rev. Cancer 4, 806-813.

Hirata, E., and Sahai, E. (2017). Tumor microenvironment and differential responses to therapy. Cold Spring Harbor Perspect. Med. 7:a026781. doi: 10. 1101/cshperspect.a026781

Ho, P. C., Bihuniak, J. D., Macintyre, A. N., Staron, M., Liu, X., Amezquita, R., et al. (2015). phosphoenolpyruvate is a metabolic checkpoint of anti-tumor T Cell responses. Cell 162, 1217-1228. doi: 10.1016/j.cell.2015.08.012

Holle, A. W., Young, J. L., and Spatz, J. P. (2016). In vitro cancer cell-ECM interactions inform in vivo cancer treatment. Adv. Drug Deliv. Rev. 97, 270279.

Holohan, C., Van Schaeybroeck, S., Longley, D. B., and Johnston, P. G. (2013). Cancer drug resistance: an evolving paradigm. Nat. Rev. Cancer 13, 714-726. doi: $10.1038 / \mathrm{nrc} 3599$

Horvat, T. Z., Adel, N. G., Dang, T.-O., Momtaz, P., Postow, M. A., Callahan, M. K., et al. (2015). Immune-related adverse events, need for systemic immunosuppression, and effects on survival and time to treatment failure in patients with melanoma treated with ipilimumab at memorial sloan kettering cancer center. J. Clin. Oncol. 33, 3193-3198. doi: 10.1200/JCO.2015.60.8448

Houriet, C., Jafari, S. M. S., Thomi, R., Schlapbach, C., Borradori, L., Yawalkar, N., et al. (2017). Canakinumab for severe hidradenitis suppurativa: preliminary experience in 2 cases. JAMA Dermatol. 153, 1195-1197.

Housman, G., Byler, S., Heerboth, S., Lapinska, K., Longacre, M., Snyder, N., et al. (2014). Drug resistance in cancer: an overview. Cancers 6, 1769-1792. doi: $10.3390 /$ cancers6031769

Hsieh, Y.-T., Gang, E. J., Geng, H., Park, E., Huantes, S., Chudziak, D., et al. (2013). Integrin alpha4 blockade sensitizes drug resistant pre-B acute lymphoblastic leukemia to chemotherapy. Blood 121, 1814-1818. doi: 10.1182/blood-201201-406272

Hu, K., Miao, L., Goodwin, T. J., Li, J., Liu, Q., and Huang, L. (2017). Quercetin remodels the tumor microenvironment to improve the permeation, retention, and antitumor effects of nanoparticles. ACS Nano 11, 4916-4925. doi: 10.1021/ acsnano.7b01522

Hu, P.-S., Li, T., Lin, J.-F., Qiu, M.-Z., Wang, D.-S., Liu, Z.-X., et al. (2020). VDRSOX2 signaling promotes colorectal cancer stemness and malignancy in an acidic microenvironment. Signal Transduct. Target. Ther. 5:183. doi: 10.1038/ s41392-020-00230-7

Huang, C. Y., Kuo, W. T., Huang, Y. C., Lee, T. C., and Yu, L. C. (2013). Resistance to hypoxia-induced necroptosis is conferred by glycolytic pyruvate scavenging of mitochondrial superoxide in colorectal cancer cells. Cell Death Dis. 4:e622. doi: $10.1038 /$ cddis.2013.149 
Hugo, W., Zaretsky, J. M., Sun, L., Song, C., Moreno, B. H., Hu-Lieskovan, S., et al. (2016). Genomic and transcriptomic features of response to Anti-PD-1 therapy in metastatic melanoma. Cell 165, 35-44. doi: 10.1016/j.cell.2016.02.065

Hui, L., and Chen, Y. (2015). Tumor microenvironment: sanctuary of the devil. Cancer Lett. 368, 7-13. doi: 10.1016/j.canlet.2015.07.039

Husain, Z., Huang, Y., Seth, P., and Sukhatme, V. P. (2013). Tumor-derived lactate modifies antitumor immune response: effect on myeloid-derived suppressor cells and NK cells. J. Immunol. 191, 1486-1495. doi: 10.4049/jimmunol. 1202702

Incio, J., Liu, H., Suboj, P., Chin, S. M., Chen, I. X., Pinter, M., et al. (2016). Obesityinduced inflammation and desmoplasia promote pancreatic cancer progression and resistance to chemotherapy. Cancer Discov. 6, 852-869. doi: 10.1158/21598290.Cd-15- 1177

Ishii, N., Araki, K., Yokobori, T., Hagiwara, K., Gantumur, D., Yamanaka, T., et al. (2019). Conophylline suppresses pancreatic cancer desmoplasia and cancerpromoting cytokines produced by cancer-associated fibroblasts. Cancer Sci. 110, 334-344. doi: 10.1111/cas.13847

Itoh, G., Chida, S., Yanagihara, K., Yashiro, M., Aiba, N., and Tanaka, M. (2017). Cancer-associated fibroblasts induce cancer cell apoptosis that regulates invasion mode of tumours. Oncogene 36, 4434-4444. doi: 10.1038/onc.2017.49

Jackaman, C., Majewski, D., Fox, S. A., Nowak, A. K., and Nelson, D. J. (2012). Chemotherapy broadens the range of tumor antigens seen by cytotoxic CD8(+) $\mathrm{T}$ cells in vivo. Cancer Immunol. Immunother. 61, 2343-2356. doi: 10.1007/ s00262-012-1307-4

Jain, R. K. (1988). Determinants of tumor blood flow: a review. Cancer Res. 48, 2641-2658.

Jeppesen, D. K., Nawrocki, A., Jensen, S. G., Thorsen, K., Whitehead, B., Howard, K. A., et al. (2014). Quantitative proteomics of fractionated membrane and lumen exosome proteins from isogenic metastatic and nonmetastatic bladder cancer cells reveal differential expression of EMT factors. Proteomics 14, 699712.

Jiang, L., Wang, Y.-J., Zhao, J., Uehara, M., Hou, Q., Kasinath, V., et al. (2020). Direct tumor killing and immunotherapy through Anti-SerpinB9 therapy. Cell 183, 1219.e18-1233.e18. doi: 10.1016/j.cell.2020.10.045

Jiang, W., Xia, J., Xie, S., Zou, R., Pan, S., Wang, Z.-W., et al. (2020). Long non-coding RNAs as a determinant of cancer drug resistance: towards the overcoming of chemoresistance via modulation of lncRNAs. Drug Resistance Updates 50:100683. doi: 10.1016/j.drup.2020.100683

Jiang, Z., Hsu, J. L., Li, Y., Hortobagyi, G. N., and Hung, M.-C. (2020). Cancer cell metabolism bolsters immunotherapy resistance by promoting an immunosuppressive tumor microenvironment. Front. Oncol. 10:1197. doi: 10. 3389/fonc.2020.01197

Jin, M. Z., and Jin, W. L. (2020). The updated landscape of tumor microenvironment and drug repurposing. Signal Transduct. Target. Ther. 5:166. doi: 10.1038/s41392-020-00280-x

Jinushi, M., Chiba, S., Yoshiyama, H., Masutomi, K., Kinoshita, I., Dosaka-Akita, H., et al. (2011). Tumor-associated macrophages regulate tumorigenicity and anticancer drug responses of cancer stem/initiating cells. Proc. Natl. Acad. Sci. U.S.A. 108, 12425-12430. doi: 10.1073/pnas.1106645108

Jo, Y., Choi, N., Kim, K., Koo, H. J., Choi, J., and Kim, H. N. (2018). Chemoresistance of cancer cells: requirements of tumor microenvironmentmimicking in vitro models in anti-cancer drug development. Theranostics 8 , 5259-5275. doi: 10.7150/thno. 29098

Joyce, J. A. (2005). Therapeutic targeting of the tumor microenvironment. Cancer Cell 7, 513-520. doi: 10.1016/j.ccr.2005.05.024

Kalluri, R., and Zeisberg, M. (2006). Fibroblasts in cancer. Nat. Rev. Cancer 6, 392-401. doi: 10.1038/nrc1877

Kamphorst, J. J., Cross, J. R., Fan, J., de Stanchina, E., Mathew, R., White, E. P., et al. (2013). Hypoxic and Ras-transformed cells support growth by scavenging unsaturated fatty acids from lysophospholipids. Proc. Natl. Acad. Sci. U.S.A. 110, 8882-8887. doi: 10.1073/pnas.1307237110

Kanazawa, Y., Yamada, T., Fujita, I., Kakinuma, D., Matsuno, K., Arai, H., et al. (2017). In vitro chemosensitivity test for gastric cancer specimens predicts effectiveness of oxaliplatin and 5-fluorouracil. Anticancer Res. 37, 6401-6405.

Kang, I., Harten, I. A., Chang, M. Y., Braun, K. R., Sheih, A., Nivison, M. P., et al. (2017). Versican deficiency significantly reduces lung inflammatory response induced by polyinosine-polycytidylic acid stimulation. J. Biol. Chem. 292, 51-63. doi: 10.1074/jbc.M116.753186
Kechagia, J. Z., Ivaska, J., and Roca-Cusachs, P. (2019). Integrins as biomechanical sensors of the microenvironment. Nat. Rev. Mol. Cell Biol. 20, 457-473.

Kesh, K., Gupta, V. K., Durden, B., Garrido, V., Mateo-Victoriano, B., Lavania, S. P., et al. (2020). Therapy resistance, cancer stem cells and ECM in cancer: the matrix reloaded. Cancers 12:3067. doi: 10.3390/cancers12103067

Kim, B. H., Yi, E. H., and Ye, S. K. (2016). Signal transducer and activator of transcription 3 as a therapeutic target for cancer and the tumor microenvironment. Arch. Pharm Res. 39, 1085-1099. doi: 10.1007/s12272-0160795-8

Kim, K., Skora, A. D., Li, Z., Liu, Q., Tam, A. J., Blosser, R. L., et al. (2014). Eradication of metastatic mouse cancers resistant to immune checkpoint blockade by suppression of myeloid-derived cells. Proc. Natl. Acad. Sci. U.S.A. 111, 11774-11779. doi: 10.1073/pnas.1410626111

Kim, S. H., Roszik, J., Grimm, E. A., and Ekmekcioglu, S. (2018). Impact of 1-Arginine metabolism on immune response and anticancer immunotherapy. Front. Oncol. 8:67. doi: 10.3389/fonc.2018.00067

Kinoshita, M., Johnson, D. L., Shatney, C. H., Lee, Y. L., and Mochizuki, H. (2001). Cancer cells surviving hypoxia obtain hypoxia resistance and maintain anti-apoptotic potential under reoxygenation. Int. J. Cancer 91, 322-326.

Kitange, G. J., Carlson, B. L., Schroeder, M. A., Grogan, P. T., Lamont, J. D., Decker, P. A., et al. (2009). Induction of MGMT expression is associated with temozolomide resistance in glioblastoma xenografts. Neuro Oncol. 11, 281-291. doi: 10.1215/15228517-2008-090

Klemm, F., and Joyce, J. A. (2015). Microenvironmental regulation of therapeutic response in cancer. Trends Cell Biol. 25, 198-213.

Kojima, Y., Acar, A., Eaton, E. N., Mellody, K. T., Scheel, C., Ben-Porath, I., et al. (2010). Autocrine TGF- $\beta$ and stromal cell-derived factor-1 (SDF-1) signaling drives the evolution of tumor-promoting mammary stromal myofibroblasts. Proc. Natl. Acad. Sci. 107, 20009-20014.

Kolosenko, I., Avnet, S., Baldini, N., Viklund, J., and De Milito, A. (2017). Therapeutic implications of tumor interstitial acidification. Semin. Cancer Biol. 43, 119-133. doi: 10.1016/j.semcancer.2017.01.008

Korneev, K. V., Atretkhany, K.-S. N., Drutskaya, M. S., Grivennikov, S. I., Kuprash, D. V., and Nedospasov, S. A. (2017). TLR-signaling and proinflammatory cytokines as drivers of tumorigenesis. Cytokine 89, 127-135.

Kovacic, P., and Osuna, J. A. Jr. (2000). Mechanisms of anti-cancer agents: emphasis on oxidative stress and electron transfer. Curr. Pharm. Des. 6, 277309. doi: 10.2174/1381612003401046

Koyama, S., Akbay, E. A., Li, Y. Y., Herter-Sprie, G. S., Buczkowski, K. A., Richards, W. G., et al. (2016). Adaptive resistance to therapeutic PD-1 blockade is associated with upregulation of alternative immune checkpoints. Nat. Commun. 7, 1-9.

Krakstad, C., and Chekenya, M. (2010). Survival signalling and apoptosis resistance in glioblastomas: opportunities for targeted therapeutics. Mol. Cancer 9:135. doi: 10.1186/1476-4598-9-135

Laoui, D., Keirsse, J., Morias, Y., Van Overmeire, E., Geeraerts, X., Elkrim, Y., et al. (2016). The tumour microenvironment harbours ontogenically distinct dendritic cell populations with opposing effects on tumour immunity. Nat. Commun. 7:13720. doi: 10.1038/ncomms13720

Larkin, J., Chiarion-Sileni, V., Gonzalez, R., Grob, J. J., Cowey, C. L., Lao, C. D., et al. (2015). Combined nivolumab and ipilimumab or monotherapy in untreated melanoma. N. Engl. J. Med. 373, 23-34. doi: 10.1056/NEJMoa1 504030

Layani-Bazar, A., Skornick, I., Berrebi, A., Pauker, M. H., Noy, E., Silberman, A., et al. (2014). Redox modulation of adjacent thiols in VLA-4 by AS101 converts myeloid leukemia cells from a drug-resistant to drug-sensitive state. Cancer Res. 74, 3092-3103. doi: 10.1158/0008-5472.Can-13-2159

Lee, C.-T., Boss, M.-K., and Dewhirst, M. W. (2014). Imaging tumor hypoxia to advance radiation oncology. Antioxidants Redox Signal. 21, 313-337.

Lee, J. G., and Wu, R. (2015). Erlotinib-cisplatin combination inhibits growth and angiogenesis through c-MYC and HIF-1 $\alpha$ in EGFR-mutated lung cancer in vitro and in vivo. Neoplasia 17, 190-200.

Lee, P., Chandel, N. S., and Simon, M. C. (2020). Cellular adaptation to hypoxia through hypoxia inducible factors and beyond. Nat. Rev. Mol. Cell Biol. 21, $268-283$.

Lei, X., Lei, Y., Li, J.-K., Du, W.-X., Li, R.-G., Yang, J., et al. (2020). Immune cells within the tumor microenvironment: biological functions and roles in cancer immunotherapy. Cancer Lett. 470, 126-133. doi: 10.1016/j.canlet.2019.11.009 
Leone, R. D., Zhao, L., Englert, J. M., Sun, I. M., Oh, M. H., Sun, I. H., et al. (2019). Glutamine blockade induces divergent metabolic programs to overcome tumor immune evasion. Science 366, 1013-1021. doi: 10.1126/science.aav2588

Leu, A. J., Berk, D. A., Lymboussaki, A., Alitalo, K., and Jain, R. K. (2000). Absence of functional lymphatics within a murine sarcoma: a molecular and functional evaluation. Cancer Res. 60, 4324-4327.

Levchenko, A., Mehta, B. M., Niu, X., Kang, G., Villafania, L., Way, D., et al. (2005). Intercellular transfer of P-glycoprotein mediates acquired multidrug resistance in tumor cells. Proc. Natl. Acad. Sci. U.S.A. 102, 1933-1938. doi: $10.1073 /$ pnas.0401851102

Li, W., and Sun, X. (2018). Recent advances in developing novel anti-cancer drugs targeting tumor hypoxic and acidic microenvironments. Recent Pat Anticancer Drug Discov. 13, 455-468. doi: 10.2174/1574892813666180831102519

Lin, S., Negulescu, A., Bulusu, S., Gibert, B., Delcros, J.-G., Ducarouge, B., et al. (2017). Non-canonical NOTCH3 signalling limits tumour angiogenesis. Nat. Commun. 8, 1-12.

Lin, Y., Xu, J., and Lan, H. (2019). Tumor-associated macrophages in tumor metastasis: biological roles and clinical therapeutic applications. J. Hematol. Oncol. 12:76. doi: 10.1186/s13045-019-0760-3

Ling, B., Watt, K., Banerjee, S., Newsted, D., Truesdell, P., Adams, J., et al. (2017). A novel immunotherapy targeting MMP-14 limits hypoxia, immune suppression and metastasis in triple-negative breast cancer models. Oncotarget 8, 58372-58385. doi: 10.18632/oncotarget.17702

Liu, J., Dang, H., and Wang, X. W. (2018). The significance of intertumor and intratumor heterogeneity in liver cancer. Exp. Mol. Med. 50:e416. doi: 10.1038/ emm.2017.165

Liu, J., Liao, S., Diop-Frimpong, B., Chen, W., Goel, S., Naxerova, K., et al. (2012). TGF- $\beta$ blockade improves the distribution and efficacy of therapeutics in breast carcinoma by normalizing the tumor stroma. Proc. Natl. Acad. Sci. U.S.A. 109, 16618-16623. doi: 10.1073/pnas.1117610109

Liu, R., Fernandez-Peñas, P., and Sebaratnam, D. F. (2017). Management of adverse events related to new cancer immunotherapy (immune checkpoint inhibitors). Med. J. Aust. 206:412. doi: 10.5694/mja16.01357

Liu, S., Ren, J., and Ten Dijke, P. (2021). Targeting TGF $\beta$ signal transduction for cancer therapy. Signal. Transduct. Target. Ther, 6:8. doi: 10.1038/s41392-02000436-9

Lobb, R. J., van Amerongen, R., Wiegmans, A., Ham, S., Larsen, J. E., and Möller, A. (2017). Exosomes derived from mesenchymal non-small cell lung cancer cells promote chemoresistance. Int. J. Cancer 141, 614-620.

Löffek, S. (2018). Transforming of the tumor microenvironment: implications for TGF- $\beta$ inhibition in the context of immune-checkpoint therapy. J. Oncol. 2018:9732939. doi: 10.1155/2018/9732939

Long, L., Assaraf, Y. G., Lei, Z.-N., Peng, H., Yang, L., Chen, Z.-S., et al. (2020). Genetic biomarkers of drug resistance: a compass of prognosis and targeted therapy in acute myeloid leukemia. Drug Resistance Updates 52:100703. doi: 10.1016/j.drup.2020.100703

Lotti, F., Jarrar, A. M., Pai, R. K., Hitomi, M., Lathia, J., Mace, A., et al. (2013). Chemotherapy activates cancer-associated fibroblasts to maintain colorectal cancer-initiating cells by IL-17A. J. Exp. Med. 210, 2851-2872. doi: 10.1084/ jem.20131195

Lu, C. W., Lin, S. C., Chien, C. W., Lin, S. C., Lee, C. T., Lin, B. W., et al. (2011). Overexpression of pyruvate dehydrogenase kinase 3 increases drug resistance and early recurrence in colon cancer. Am. J. Pathol. 179, 1405-1414. doi: 10.1016/j.ajpath.2011.05.050

Luga, V., Zhang, L., Viloria-Petit, A. M., Ogunjimi, A. A., Inanlou, M. R., Chiu, E., et al. (2012). Exosomes mediate stromal mobilization of autocrine Wnt-PCP signaling in breast cancer cell migration. Cell 151, 1542-1556. doi: 10.1016/j. cell.2012.11.024

Luo, W., Zhong, J., Chang, R., Hu, H., Pandey, A., and Semenza, G. L. (2010). Hsp70 and CHIP selectively mediate ubiquitination and degradation of hypoxia-inducible factor (HIF)-1alpha but Not HIF-2alpha. J. Biol. Chem. 285, 3651-3663. doi: 10.1074/jbc.M109.068577

Luraghi, P., Reato, G., Cipriano, E., Sassi, F., Orzan, F., Bigatto, V., et al. (2014). MET signaling in colon cancer stem-like cells blunts the therapeutic response to EGFR inhibitors. Cancer Res. 74, 1857-1869. doi: 10.1158/0008-5472.Can13-2340-t

Lv, M. M., Zhu, X. Y., Chen, W. X., Zhong, S. L., Hu, Q., Ma, T. F., et al. (2014). Exosomes mediate drug resistance transfer in MCF-7 breast cancer cells and a probable mechanism is delivery of P-glycoprotein. Tumour. Biol. 35, 10773-10779. doi: 10.1007/s13277-014-2377-z

Ma, Z., Yuan, D., Cheng, X., Tuo, B., Liu, X., and Li, T. (2020). Function of ion transporters in maintaining acid-base homeostasis of the mammary gland and the pathophysiological role in breast cancer. Am. J. Physiol. Regul. Integr. Comp. Physiol. 318, R98-R111.

Maeda, H., and Khatami, M. (2018). Analyses of repeated failures in cancer therapy for solid tumors: poor tumor-selective drug delivery, low therapeutic efficacy and unsustainable costs. Clin. Transl. Med. 7:11.

Maj, T., Wang, W., Crespo, J., Zhang, H., Wang, W., Wei, S., et al. (2017). Oxidative stress controls regulatory $\mathrm{T}$ cell apoptosis and suppressor activity and PD-L1blockade resistance in tumor. Nat. Immunol. 18, 1332-1341. doi: 10.1038/ni. 3868

Maman, S., and Witz, I. P. (2018). A history of exploring cancer in context. Nat. Rev. Cancer 18, 359-376. doi: 10.1038/s41568-018-0006-7

Mangan, M. S., Vega-Ramos, J., Joeckel, L. T., Mitchell, A. J., Rizzitelli, A., Roediger, B., et al. (2017). Serpinb9 is a marker of antigen cross-presenting dendritic cells. Mol. Immunol. 82, 50-56. doi: 10.1016/j.molimm.2016.12.011

Manning, B. D., and Cantley, L. C. (2007). AKT/PKB signaling: navigating downstream. Cell 129, 1261-1274. doi: 10.1016/j.cell.2007.06.009

Mantoni, T. S., Lunardi, S., Al-Assar, O., Masamune, A., and Brunner, T. B. (2011). Pancreatic stellate cells radioprotect pancreatic cancer cells through $\beta 1$-integrin signaling. Cancer Res. 71, 3453-3458. doi: 10.1158/0008-5472.Can-10-1633

Mantovani, A., Allavena, P., Sica, A., and Balkwill, F. (2008). Cancer-related inflammation. Nature 454, 436-444. doi: 10.1038/nature07205

Mantovani, A., Marchesi, F., Malesci, A., Laghi, L., and Allavena, P. (2017). Tumour-associated macrophages as treatment targets in oncology. Nat. Rev. Clin. Oncol. 14, 399-416. doi: 10.1038/nrclinonc.2016.217

Martínez-Lostao, L., Anel, A., and Pardo, J. (2015). How do cytotoxic lymphocytes kill cancer cells? Clin. Cancer Res, 21, 5047-5056. doi: 10.1158/1078-0432.Ccr15-0685

Martinez-Outschoorn, U. E., Peiris-Pagés, M., Pestell, R. G., Sotgia, F., and Lisanti, M. P. (2017). Cancer metabolism: a therapeutic perspective. Nat. Rev. Clin. Oncol. 14, 11-31. doi: 10.1038/nrclinonc.2016.60

Martinkova, E., Maglott, A., Leger, D. Y., Bonnet, D., Stiborova, M., Takeda, K., et al. (2010). $\alpha 5 \beta 1$ integrin antagonists reduce chemotherapy-induced premature senescence and facilitate apoptosis in human glioblastoma cells. Int. J. Cancer 127, 1240-1248. doi: 10.1002/ijc.25187

Martino, M. M., Briquez, P. S., Güç, E., Tortelli, F., Kilarski, W. W., Metzger, S., et al. (2014). Growth factors engineered for super-affinity to the extracellular matrix enhance tissue healing. Science 343, 885-888.

Mashouri, L., Yousefi, H., Aref, A. R., Ahadi, A. M., Molaei, F., and Alahari, S. K. (2019). Exosomes: composition, biogenesis, and mechanisms in cancer metastasis and drug resistance. Mol. Cancer 18:75. doi: 10.1186/s12943-0190991-5

Matsunuma, S., Handa, S., Kamei, D., Yamamoto, H., Okuyama, K., and Kato, Y. (2019). Oxaliplatin induces prostaglandin E2 release in vascular endothelial cells. Cancer Chemother. Pharmacol. 84, 345-350.

Mazzarella, L., and Curigliano, G. (2018). A new approach to assess drug sensitivity in cells for novel drug discovery. Expert Opin. Drug Discov. 13, 339-346. doi: 10.1080/17460441.2018.1437136

McAndrews, K. M., McGrail, D. J., Ravikumar, N., and Dawson, M. R. (2015). Mesenchymal stem cells induce directional migration of invasive breast cancer cells through TGF- $\beta$. Sci. Rep. 5:16941. doi: 10.1038/srep16941

Meijer, T. W., Kaanders, J. H., Span, P. N., and Bussink, J. (2012). Targeting hypoxia, HIF-1, and tumor glucose metabolism to improve radiotherapy efficacy. Clin. Cancer Res. 18, 5585-5594. doi: 10.1158/1078-0432.Ccr-12-0858

Meurette, O., and Mehlen, P. (2018). Notch signaling in the tumor microenvironment. Cancer Cell 34, 536-548. doi: 10.1016/j.ccell.2018.07.009

Miller, K. D., Nogueira, L., Mariotto, A. B., Rowland, J. H., Yabroff, K. R., Alfano, C. M., et al. (2019). Cancer treatment and survivorship statistics, 2019. CA Cancer J. Clin. 69, 363-385. doi: 10.3322/caac.21565

Milman, N., Ginini, L., and Gil, Z. (2019). Exosomes and their role in tumorigenesis and anticancer drug resistance. Drug Resistance Updates 45, 1-12. doi: 10.1016/ j.drup.2019.07.003

Milosevic, M., Fyles, A., Hedley, D., and Hill, R. (2004). The human tumor microenvironment: invasive (needle) measurement of oxygen and interstitial fluid pressure. Semin. Radiat. Oncol. 14, 249-258. 
Mohammad, R. M., Muqbil, I., Lowe, L., Yedjou, C., Hsu, H. Y., Lin, L. T., et al. (2015). Broad targeting of resistance to apoptosis in cancer. Semin. Cancer Biol. 35(Suppl.(0)), S78-S103. doi: 10.1016/j.semcancer.2015.03.001

Moloney, J. N., and Cotter, T. G. (2018). ROS signalling in the biology of cancer. Semin. Cell Dev. Biol. 80, 50-64.

Monferran, S., Skuli, N., Delmas, C., Favre, G., Bonnet, J., Cohen-Jonathan-Moyal, E., et al. (2008). $\alpha v \beta 3$ and $\alpha v \beta 5$ integrins control glioma cell response to ionising radiation through ILK and RhoB. Int. J. Cancer 123, 357-364. doi: 10.1002/ijc. 23498

Morrot, A., da Fonseca, L. M., Salustiano, E. J., Gentile, L. B., Conde, L., Filardy, A. A., et al. (2018). Metabolic symbiosis and immunomodulation: how tumor cell-derived lactate may disturb innate and adaptive immune responses. Front. Oncol. 8:81. doi: 10.3389/fonc.2018.00081

Morrow, K., Hernandez, C. P., Raber, P., Del Valle, L., Wilk, A. M., Majumdar, S., et al. (2013). Anti-leukemic mechanisms of pegylated arginase I in acute lymphoblastic T-cell leukemia. Leukemia 27, 569-577. doi: 10.1038/leu.2012. 247

Nagaraj, S., Gupta, K., Pisarev, V., Kinarsky, L., Sherman, S., Kang, L., et al. (2007). Altered recognition of antigen is a mechanism of CD8+ T cell tolerance in cancer. Nat. Med. 13, 828-835. doi: 10.1038/nm1609

Nagathihalli, N. S., Castellanos, J. A., Shi, C., Beesetty, Y., Reyzer, M. L., Caprioli, R., et al. (2015). Signal transducer and activator of transcription 3, mediated remodeling of the tumor microenvironment results in enhanced tumor drug delivery in a mouse model of pancreatic cancer. Gastroenterology 149, 1932.e91943.e9. doi: 10.1053/j.gastro.2015.07.058

Najafi, M., Farhood, B., and Mortezaee, K. (2019). Extracellular matrix (ECM) stiffness and degradation as cancer drivers. J. Cell Biochem. 120, 2782-2790. doi: $10.1002 /$ jcb. 27681

Nishimoto, A., Kugimiya, N., Hosoyama, T., Enoki, T., Li, T. S., and Hamano, K. (2014). HIF-1 $\alpha$ activation under glucose deprivation plays a central role in the acquisition of anti-apoptosis in human colon cancer cells. Int. J. Oncol. 44, 2077-2084. doi: 10.3892/ijo.2014.2367

Nokin, M. J., Durieux, F., Bellier, J., Peulen, O., Uchida, K., Spiegel, D. A., et al. (2017). Hormetic potential of methylglyoxal, a side-product of glycolysis, in switching tumours from growth to death. Sci. Rep. 7:11722. doi: 10.1038/ s41598-017-12119-7

Noy, R., and Pollard, J. W. (2014). Tumor-associated macrophages: from mechanisms to therapy. Immunity 41, 49-61. doi: 10.1016/j.immuni.2014.06. 010

Obenauf, A. C., Zou, Y., Ji, A. L., Vanharanta, S., Shu, W., Shi, H., et al. (2015). Therapy-induced tumour secretomes promote resistance and tumour progression. Nature 520, 368-372. doi: 10.1038/nature14336

O’Donnell, J. S., Long, G. V., Scolyer, R. A., Teng, M. W. L., and Smyth, M. J. (2017). Resistance to PD1/PDL1 checkpoint inhibition. Cancer Treatm. Rev. 52, 71-81. doi: $10.1016 /$ j.ctrv.2016.11.007

Ogawa, R., Ishiguro, H., Kuwabara, Y., Kimura, M., Mitsui, A., Mori, Y., et al. (2008). Identification of candidate genes involved in the radiosensitivity of esophageal cancer cells by microarray analysis. Dis. Esophagus 21, 288-297. doi: 10.1111/j.1442-2050.2007.00759.x

Oh, M. H., Sun, I. H., Zhao, L., Leone, R. D., Sun, I. M., Xu, W., et al. (2020). Targeting glutamine metabolism enhances tumor-specific immunity by modulating suppressive myeloid cells. J. Clin. Invest. 130, 3865-3884. doi: $10.1172 /$ jci131859

Olive, K. P., Jacobetz, M. A., Davidson, C. J., Gopinathan, A., McIntyre, D., Honess, D., et al. (2009). Inhibition of Hedgehog signaling enhances delivery of chemotherapy in a mouse model of pancreatic cancer. Science 324, 1457-1461.

Orimo, A., Gupta, P. B., Sgroi, D. C., Arenzana-Seisdedos, F., Delaunay, T., Naeem, R., et al. (2005). Stromal fibroblasts present in invasive human breast carcinomas promote tumor growth and angiogenesis through elevated SDF1/CXCL12 secretion. Cell 121, 335-348. doi: 10.1016/j.cell.2005.02.034

O'Sullivan, D., van der Windt, G. J., Huang, S. C., Curtis, J. D., Chang, C. H., Buck, M. D., et al. (2014). Memory CD8(+) T cells use cell-intrinsic lipolysis to support the metabolic programming necessary for development. Immunity 41, 75-88. doi: 10.1016/j.immuni.2014.06.005

OuYang, L. Y., Wu, X. J., Ye, S. B., Zhang, R. X., Li, Z. L., Liao, W., et al. (2015). Tumor-induced myeloid-derived suppressor cells promote tumor progression through oxidative metabolism in human colorectal cancer. J. Transl. Med. 13:47. doi: 10.1186/s12967-015-0410-7
Ozawa, P. M. M., Alkhilaiwi, F., Cavalli, I. J., Malheiros, D., de Souza Fonseca Ribeiro, E. M., and Cavalli, L. R. (2018). Extracellular vesicles from triplenegative breast cancer cells promote proliferation and drug resistance in nontumorigenic breast cells. Breast Cancer Res. Treat. 172, 713-723. doi: 10.1007/ s10549-018-4925-5

Paauwe, M., Schoonderwoerd, M. J., Helderman, R. F., Harryvan, T. J., Groenewoud, A., van Pelt, G. W., et al. (2018). Endoglin expression on cancer-associated fibroblasts regulates invasion and stimulates colorectal cancer metastasis. Clin. Cancer Res. 24, 6331-6344.

Padera, T. P., Stoll, B. R., Tooredman, J. B., Capen, D., di Tomaso, E., and Jain, R. K. (2004). Cancer cells compress intratumour vessels. Nature 427, 695-695.

Paolicchi, E., Gemignani, F., Krstic-Demonacos, M., Dedhar, S., Mutti, L., and Landi, S. (2016). Targeting hypoxic response for cancer therapy. Oncotarget 7 , 13464-13478. doi: 10.18632/oncotarget.7229

Paolillo, M., and Schinelli, S. (2017). Integrins and exosomes, a dangerous liaison in cancer progression. Cancers 9:95. doi: 10.3390/cancers9080095

Papapetrou, E. P. (2016). Patient-derived induced pluripotent stem cells in cancer research and precision oncology. Nat. Med. 22, 1392-1401. doi: 10.1038/nm. 4238

Park, C. C., Zhang, H. J., Yao, E. S., Park, C. J., and Bissell, M. J. (2008). B1Integrin inhibition dramatically enhances radiotherapy efficacy in human breast cancer xenografts. Cancer Res. 68, 4398-4405. doi: 10.1158/0008-5472.Can-07-6390

Patel, S. A., and Minn, A. J. (2018). Combination cancer therapy with immune checkpoint blockade: mechanisms and strategies. Immunity 48, 417-433. doi: 10.1016/j.immuni.2018.03.007

Paz-Ares, L., Garon, E., Ardizzoni, A., Barlesi, F., Cho, B., de Castro Junior, G., et al. (2019). CANOPY phase III program: three studies evaluating canakinumab in patients with non-small cell lung cancer (NSCLC). Ann. Oncol. 30, v654-v655.

Pei, G. T., Wu, C. W., and Lin, W. W. (2010). Hypoxia-induced decoy receptor 2 gene expression is regulated via a hypoxia-inducible factor 1alpha-mediated mechanism. Biochem. Biophys. Res. Commun. 391, 1274-1279. doi: 10.1016/j. bbrc.2009.12.058

Petrova, V., Annicchiarico-Petruzzelli, M., Melino, G., and Amelio, I. (2018). The hypoxic tumour microenvironment. Oncogenesis 7, 1-13.

Pickup, M. W., Mouw, J. K., and Weaver, V. M. (2014). The extracellular matrix modulates the hallmarks of cancer. EMBO Rep. 15, 1243-1253. doi: 10.15252/ embr.201439246

Podar, K., Zimmerhackl, A., Fulciniti, M., Tonon, G., Hainz, U., Tai, Y. T., et al. (2011). The selective adhesion molecule inhibitor Natalizumab decreases multiple myeloma cell growth in the bone marrow microenvironment: therapeutic implications. Br. J. Haematol. 155, 438-448. doi: 10.1111/j.13652141.2011.08864.x

Pouysségur, J., Dayan, F., and Mazure, N. M. (2006). Hypoxia signalling in cancer and approaches to enforce tumour regression. Nature 441, 437-443.

Prima, V., Kaliberova, L. N., Kaliberov, S., Curiel, D. T., and Kusmartsev, S. (2017). COX2/mPGES1/PGE2 pathway regulates PD-L1 expression in tumorassociated macrophages and myeloid-derived suppressor cells. Proc. Natl. Acad. Sci. U.S.A. 114, 1117-1122. doi: 10.1073/pnas.1612920114

Pucino, V., Bombardieri, M., Pitzalis, C., and Mauro, C. (2017). Lactate at the crossroads of metabolism, inflammation, and autoimmunity. Eur. J. Immunol. 47, 14-21. doi: 10.1002/eji.201646477

Purcell, J. W., Tanlimco, S. G., Hickson, J., Fox, M., Sho, M., Durkin, L., et al. (2018). LRRC15 is a novel mesenchymal protein and stromal target for antibody-drug conjugates. Cancer Res. 78, 4059-4072. doi: 10.1158/0008-5472.Can-18-0327

Pusch, S., Krausert, S., Fischer, V., Balss, J., Ott, M., Schrimpf, D., et al. (2017). Panmutant IDH1 inhibitor BAY 1436032 for effective treatment of IDH1 mutant astrocytoma in vivo. Acta Neuropathol. 133, 629-644. doi: 10.1007/s00401-017$1677-y$

Qiao, Y., Zhang, C., Li, A., Wang, D., Luo, Z., Ping, Y., et al. (2018). IL6 derived from cancer-associated fibroblasts promotes chemoresistance via CXCR7 in esophageal squamous cell carcinoma. Oncogene 37, 873-883. doi: 10.1038/onc. 2017.387

Quail, D. F., and Joyce, J. A. (2013). Microenvironmental regulation of tumor progression and metastasis. Nat. Med. 19, 1423-1437. doi: 10.1038/nm.3394

Raghunand, N., Mahoney, B. P., and Gillies, R. J. (2003). Tumor acidity, ion trapping and chemotherapeutics. II. pH-dependent partition coefficients predict importance of ion trapping on pharmacokinetics of weakly basic 
chemotherapeutic agents. Biochem. Pharmacol. 66, 1219-1229. doi: 10.1016/ s0006-2952(03)00468-4

Räihä, M. R., and Puolakkainen, P. A. (2018). Tumor-associated macrophages (TAMs) as biomarkers for gastric cancer: a review. Chronic Dis. Transl. Med. 4, 156-163. doi: 10.1016/j.cdtm.2018.07.001

Ramapriyan, R., Caetano, M. S., Barsoumian, H. B., Mafra, A. C. P., Zambalde, E. P., Menon, H., et al. (2019). Altered cancer metabolism in mechanisms of immunotherapy resistance. Pharmacol. Ther. 195, 162-171. doi: 10.1016/j. pharmthera.2018.11.004

Räsänen, K., and Vaheri, A. (2010). Activation of fibroblasts in cancer stroma. Exp. Cell Res. 316, 2713-2722. doi: 10.1016/j.yexcr.2010.04.032

Ren, J., Ding, L., Zhang, D., Shi, G., Xu, Q., Shen, S., et al. (2018). Carcinomaassociated fibroblasts promote the stemness and chemoresistance of colorectal cancer by transferring exosomal lncRNA H19. Theranostics 8:3932.

Restifo, N. P., Smyth, M. J., and Snyder, A. (2016). Acquired resistance to immunotherapy and future challenges. Nat. Rev. Cancer 16, 121-126. doi: 10. 1038/nrc.2016.2

Richards, K. E., Zeleniak, A. E., Fishel, M. L., Wu, J., Littlepage, L. E., and Hill, R. (2017). Cancer-associated fibroblast exosomes regulate survival and proliferation of pancreatic cancer cells. Oncogene 36, 1770-1778.

Ridker, P. M., MacFadyen, J. G., Thuren, T., Everett, B. M., Libby, P., and Glynn, R. J. (2017). Effect of interleukin-1 $\beta$ inhibition with canakinumab on incident lung cancer in patients with atherosclerosis: exploratory results from a randomised, double-blind, placebo-controlled trial. Lancet 390, 1833-1842. doi: 10.1016/s0140-6736(17)32247-x

Ritter, V. (2017). Role of Bcl-2 Protein Family Members and Associated Mitochondrial Factors in Hypoxia-Mediated Resistance of Tumor Cells to Apoptosis and Radiotherapy. Duisburg: Universität Duisburg-Essen.

Robert, C., Schachter, J., Long, G. V., Arance, A., Grob, J. J., Mortier, L., et al. (2015). Pembrolizumab versus ipilimumab in advanced melanoma. N. Engl. J. Med. 372, 2521-2532. doi: 10.1056/NEJMoa1503093

Rohwer, N., Dame, C., Haugstetter, A., Wiedenmann, B., Detjen, K., Schmitt, C. A., et al. (2010). Hypoxia-inducible factor 1alpha determines gastric cancer chemosensitivity via modulation of p53 and NF-kappaB. PLoS One 5:e12038. doi: 10.1371/journal.pone.0012038

Roma-Rodrigues, C., Mendes, R., Baptista, P. V., and Fernandes, A. R. (2019). Targeting tumor microenvironment for cancer therapy. Int. J. Mol. Sci. 20:840. doi: $10.3390 / \mathrm{ijms} 20040840$

Roswall, P., Bocci, M., Bartoschek, M., Li, H., Kristiansen, G., Jansson, S., et al. (2018). Microenvironmental control of breast cancer subtype elicited through paracrine platelet-derived growth factor-CC signaling. Nat. Med. 24, 463-473. doi: $10.1038 / \mathrm{nm} .4494$

Ruffell, B., and Coussens, L. M. (2015). Macrophages and therapeutic resistance in cancer. Cancer Cell 27, 462-472. doi: 10.1016/j.ccell.2015.02.015

Safaei, R., Larson, B. J., Cheng, T. C., Gibson, M. A., Otani, S., Naerdemann, W., et al. (2005). Abnormal lysosomal trafficking and enhanced exosomal export of cisplatin in drug-resistant human ovarian carcinoma cells. Mol. Cancer Ther. 4, 1595-1604. doi: 10.1158/1535-7163.Mct-05-0102

Saleh, R., and Elkord, E. (2020). Acquired resistance to cancer immunotherapy: role of tumor-mediated immunosuppression. Semin. Cancer Biol. 65, 13-27. doi: 10.1016/j.semcancer.2019.07.017

Salmaninejad, A., Valilou, S. F., Soltani, A., Ahmadi, S., Abarghan, Y. J., Rosengren, R. J., et al. (2019). Tumor-associated macrophages: role in cancer development and therapeutic implications. Cell Oncol. 42, 591-608. doi: 10.1007/s13402019-00453-z

Salnikov, A. V., Iversen, V. V., Koisti, M., Sundberg, C., Johansson, L., Stuhr, L. B., et al. (2003). Lowering of tumor interstitial fluid pressure specifically augments efficacy of chemotherapy. FASEB J. 17, 1756-1758.

Salony, Solé, X., Alves, C. P., Dey-Guha, I., Ritsma, L., Boukhali, M., et al. (2016). AKT inhibition promotes nonautonomous cancer cell survival. Mol. Cancer Ther. 15, 142-153. doi: 10.1158/1535-7163.Mct-15-0414

Salvagno, C., Ciampricotti, M., Tuit, S., Hau, C.-S., van Weverwijk, A., Coffelt, S. B., et al. (2019). Therapeutic targeting of macrophages enhances chemotherapy efficacy by unleashing type I interferon response. Nat. Cell Biol. 21, 511-521.

Samavati, L., Rastogi, R., Du, W., Hüttemann, M., Fite, A., and Franchi, L. (2009). STAT3 tyrosine phosphorylation is critical for interleukin 1 beta and interleukin-6 production in response to lipopolysaccharide and live bacteria. Mol. Immunol. 46, 1867-1877. doi: 10.1016/j.molimm.2009.02.018
Sato, N., Kohi, S., Hirata, K., and Goggins, M. (2016). Role of hyaluronan in pancreatic cancer biology and therapy: once again in the spotlight. Cancer Sci. 107, 569-575. doi: $10.1111 /$ cas. 12913

Sauvant, C., Nowak, M., Wirth, C., Schneider, B., Riemann, A., Gekle, M., et al. (2008). Acidosis induces multi-drug resistance in rat prostate cancer cells (AT1) in vitro and in vivo by increasing the activity of the p-glycoprotein via activation of p38. Int. J. Cancer 123, 2532-2542. doi: 10.1002/ijc.23818

Sawa-Wejksza, K., and Kandefer-Szerszeń, M. (2018). Tumor-associated macrophages as target for antitumor therapy. Arch. Immunol. Ther. Exp. 66, 97-111. doi: 10.1007/s00005-017-0480-8

Scalici, J. M., Harrer, C., Allen, A., Jazaeri, A., Atkins, K. A., McLachlan, K. R., et al. (2014). Inhibition of $\alpha 4 \beta 1$ integrin increases ovarian cancer response to carboplatin. Gynecol. Oncol. 132, 455-461. doi: 10.1016/j.ygyno.2013.12.031

Scannevin, R. H., Alexander, R., Haarlander, T. M., Burke, S. L., Singer, M., Huo, C., et al. (2017). Discovery of a highly selective chemical inhibitor of matrix metalloproteinase-9 (MMP-9) that allosterically inhibits zymogen activation. J. Biol. Chem. 292, 17963-17974. doi: 10.1074/jbc.M117.806075

Schenk, K. M., Reuss, J. E., Choquette, K., and Spira, A. I. (2019). A review of canakinumab and its therapeutic potential for non-small cell lung cancer. Anti Cancer Drugs 30, 879-885.

Schneider, A., and Simons, M. (2013). Exosomes: vesicular carriers for intercellular communication in neurodegenerative disorders. Cell Tissue Res. 352, 33-47.

Schrader, J., Gordon-Walker, T. T., Aucott, R. L., van Deemter, M., Quaas, A., Walsh, S., et al. (2011). Matrix stiffness modulates proliferation, chemotherapeutic response, and dormancy in hepatocellular carcinoma cells. Hepatology 53, 1192-1205. doi: 10.1002/hep.24108

Seguin, L., Kato, S., Franovic, A., Camargo, M. F., Lesperance, J., Elliott, K. C., et al. (2014). An integrin $\beta 3$-KRAS-RalB complex drives tumour stemness and resistance to EGFR inhibition. Nat. Biol. 16, 457-468.

Sehested, T. S., Bjerre, J., Ku, S., Chang, A., Jahansouz, A., Owens, D. K., et al. (2019). Cost-effectiveness of Canakinumab for prevention of recurrent cardiovascular events. JAMA Cardiol. 4, 128-135.

Semenza, G. L. (2013). Cancer-stromal cell interactions mediated by hypoxiainducible factors promote angiogenesis, lymphangiogenesis, and metastasis. Oncogene 32, 4057-4063.

Senthebane, D. A., Jonker, T., Rowe, A., Thomford, N. E., Munro, D., Dandara, C., et al. (2018). The role of tumor microenvironment in chemoresistance: 3D extracellular matrices as accomplices. Int. J. Mol. Sci. 19:2861.

Sevick, E. M., and Jain, R. K. (1989). Geometric resistance to blood flow in solid tumors perfused ex vivo: effects of tumor size and perfusion pressure. Cancer Res. 49, 3506-3512.

Shackelford, D. B., Vasquez, D. S., Corbeil, J., Wu, S., Leblanc, M., Wu, C. L., et al. (2009). mTOR and HIF-1alpha-mediated tumor metabolism in an LKB1 mouse model of Peutz-Jeghers syndrome. Proc. Natl. Acad. Sci. U.S.A. 106, 11137-11142. doi: 10.1073/pnas.0900465106

Shalabi, H., Kraft, I. L., Wang, H. W., Yuan, C. M., Yates, B., Delbrook, C., et al. (2018). Sequential loss of tumor surface antigens following chimeric antigen receptor T-cell therapies in diffuse large B-cell lymphoma. Haematologica 103, e215-e218. doi: 10.3324/haematol.2017.183459

Sharma, P., Hu-Lieskovan, S., Wargo, J. A., and Ribas, A. (2017). Primary, adaptive, and acquired resistance to cancer immunotherapy. Cell 168, 707-723. doi: 10.1016/j.cell.2017.01.017

Shaw, R. J., Bardeesy, N., Manning, B. D., Lopez, L., Kosmatka, M., DePinho, R. A., et al. (2004). The LKB1 tumor suppressor negatively regulates mTOR signaling. Cancer Cell 6, 91-99. doi: 10.1016/j.ccr.2004.06.007

Shayan, G., Srivastava, R., Li, J., Schmitt, N., Kane, L. P., and Ferris, R. L. (2017). Adaptive resistance to anti-PD1 therapy by Tim-3 upregulation is mediated by the PI3K-Akt pathway in head and neck cancer. OncoImmunology 6:e1261779. doi: 10.1080/2162402X.2016.1261779

Shedden, K., Xie, X. T., Chandaroy, P., Chang, Y. T., and Rosania, G. R. (2003). Expulsion of small molecules in vesicles shed by cancer cells: association with gene expression and chemosensitivity profiles. Cancer Res. 63, 4331-4337.

Shiga, K., Hara, M., Nagasaki, T., Sato, T., Takahashi, H., and Takeyama, H. (2015). Cancer-associated fibroblasts: their characteristics and their roles in tumor growth. Cancers 7, 2443-2458. doi: 10.3390/cancers7040902

Shree, T., Olson, O. C., Elie, B. T., Kester, J. C., Garfall, A. L., Simpson, K., et al. (2011). Macrophages and cathepsin proteases blunt chemotherapeutic response in breast cancer. Genes Dev. 25, 2465-2479. doi: 10.1101/gad.180331.111 
Singh, D., Arora, R., Kaur, P., Singh, B., Mannan, R., and Arora, S. (2017). Overexpression of hypoxia-inducible factor and metabolic pathways: possible targets of cancer. Cell Biosci. 7, 1-9.

Socinski, M. A., Jotte, R. M., Cappuzzo, F., Orlandi, F., Stroyakovskiy, D., Nogami, N., et al. (2018). Atezolizumab for first-line treatment of metastatic nonsquamous NSCLC. N. Engl. J. Med. 378, 2288-2301.

Solinas, G., Schiarea, S., Liguori, M., Fabbri, M., Pesce, S., Zammataro, L., et al. (2010). Tumor-conditioned macrophages secrete migration-stimulating factor: a new marker for M2-polarization, influencing tumor cell motility. J. Immunol. 185, 642-652. doi: 10.4049/jimmunol.1000413

Steinbichler, T. B., Dudás, J., Skvortsov, S., Ganswindt, U., Riechelmann, H., and Skvortsova, I. I. (2018). Therapy resistance mediated by cancer stem cells. Semin. Cancer Biol. 53, 156-167. doi: 10.1016/j.semcancer.2018.11.006

Steinbichler, T. B., Dudás, J., Skvortsov, S., Ganswindt, U., Riechelmann, H., and Skvortsova, I. I. (2019). Therapy resistance mediated by exosomes. Mol. Cancer 18:58. doi: 10.1186/s12943-019-0970-x

Stepka, P., Vsiansky, V., Raudenska, M., Gumulec, J., Adam, V., and Masarik, M. (2020). Metabolic and amino acid alterations of the tumor microenvironment. Curr. Med. Chem. 27:1. doi: 10.2174/0929867327666200207114658

Stohrer, M., Boucher, Y., Stangassinger, M., and Jain, R. K. (2000). Oncotic pressure in solid tumors is elevated. Cancer Res. 60, 4251-4255.

Stone, M. L., Chiappinelli, K. B., Li, H., Murphy, L. M., Travers, M. E., Topper, M. J., et al. (2017). Epigenetic therapy activates type I interferon signaling in murine ovarian cancer to reduce immunosuppression and tumor burden. Proc. Natl. Acad. Sci. U.S.A. 114, E10981-E10990. doi: 10.1073/pnas.1712514114

Straussman, R., Morikawa, T., Shee, K., Barzily-Rokni, M., Qian, Z. R., Du, J., et al. (2012). Tumour micro-environment elicits innate resistance to RAF inhibitors through HGF secretion. Nature 487, 500-504. doi: 10.1038/nature11183

Strick, R., Strissel, P. L., Baylin, S. B., and Chiappinelli, K. B. (2016). Unraveling the molecular pathways of DNA-methylation inhibitors: human endogenous retroviruses induce the innate immune response in tumors. Oncoimmunology 5:e1122160. doi: 10.1080/2162402x.2015.1122160

Studebaker, A. W., Storci, G., Werbeck, J. L., Sansone, P., Sasser, A. K., Tavolari, S., et al. (2008). Fibroblasts isolated from common sites of breast cancer metastasis enhance cancer cell growth rates and invasiveness in an interleukin6-dependent manner. Cancer Res. 68, 9087-9095. doi: 10.1158/0008-5472.Can08-0400

Stupp, R., Hegi, M. E., Gorlia, T., Erridge, S. C., Perry, J., Hong, Y.-K., et al. (2014). Cilengitide combined with standard treatment for patients with newly diagnosed glioblastoma with methylated MGMT promoter (CENTRIC EORTC 26071-22072 study): a multicentre, randomised, open-label, phase 3 trial. Lancet Oncol. 15, 1100-1108. doi: 10.1016/S1470-2045(14)70379-1

Su, S., Chen, J., Yao, H., Liu, J., Yu, S., Lao, L., et al. (2018). CD10(+)GPR77(+) Cancer-associated fibroblasts promote cancer formation and chemoresistance by sustaining cancer stemness. Cell 172, 841.e16-856.e16. doi: 10.1016/j.cell. 2018.01.009

Sun, Y. (2016). Tumor microenvironment and cancer therapy resistance. Cancer Lett. 380, 205-215. doi: 10.1016/j.canlet.2015.07.044

Sun, Y., Campisi, J., Higano, C., Beer, T. M., Porter, P., Coleman, I., et al. (2012). Treatment-induced damage to the tumor microenvironment promotes prostate cancer therapy resistance through WNT16B. Nat. Med. 18, 1359-1368. doi: $10.1038 / \mathrm{nm} .2890$

Sung, B. H., Ketova, T., Hoshino, D., Zijlstra, A., and Weaver, A. M. (2015). Directional cell movement through tissues is controlled by exosome secretion. Nat. Commun. 6:7164. doi: 10.1038/ncomms 8164

Supuran, C. T. (2018). Carbonic anhydrase inhibitors as emerging agents for the treatment and imaging of hypoxic tumors. Expert Opin. Invest. Drugs 27, 963-970.

Szakács, G., Paterson, J. K., Ludwig, J. A., Booth-Genthe, C., and Gottesman, M. M. (2006). Targeting multidrug resistance in cancer. Nat. Rev. Drug Discov. 5, 219-234. doi: 10.1038/nrd1984

Szebeni, G. J., Vizler, C., Nagy, L. I., Kitajka, K., and Puskas, L. G. (2016). protumoral inflammatory myeloid cells as emerging therapeutic targets. Int. J. Mol. Sci. 17:1958. doi: 10.3390/ijms17111958

Taipale, M., Jarosz, D. F., and Lindquist, S. (2010). HSP90 at the hub of protein homeostasis: emerging mechanistic insights. Nat. Rev. Mol. Cell Biol. 11, 515528. doi: $10.1038 / \mathrm{nrm} 2918$
Tan, H. Y., Wang, N., Lam, W., Guo, W., Feng, Y., and Cheng, Y. C. (2018). Targeting tumour microenvironment by tyrosine kinase inhibitor. Mol. Cancer 17:43. doi: 10.1186/s12943-018-0800-6

Tan, Q., Saggar, J. K., Yu, M., Wang, M., and Tannock, I. F. (2015). Mechanisms of drug resistance related to the microenvironment of solid tumors and possible strategies to inhibit them. Cancer J. 21, 254-262.

Tanaka, H., Yoshizawa, H., Yamaguchi, Y., Ito, K., Kagamu, H., Suzuki, E., et al. (1999). Successful adoptive immunotherapy of murine poorly immunogenic tumor with specific effector cells generated from gene-modified tumor-primed lymph node cells. J. Immunol. 162, 3574-3582.

Tang, Y. A., Chen, Y. F., Bao, Y., Mahara, S., Yatim, S., Oguz, G., et al. (2018). Hypoxic tumor microenvironment activates GLI2 via HIF- $1 \alpha$ and TGF- $\beta 2$ to promote chemoresistance in colorectal cancer. Proc. Natl. Acad. Sci. U.S.A. 115, E5990-E5999. doi: 10.1073/pnas.1801348115

Tatum, J. L. (2006). Hypoxia: importance in tumor biology, noninvasive measurement by imaging, and value of its measurement in the management of cancer therapy. Int. J. Radiat. Biol. 82, 699-757.

Thomasset, N., Lochter, A., Sympson, C. J., Lund, L. R., Williams, D. R., Behrendtsen, O., et al. (1998). Expression of autoactivated stromelysin-1 in mammary glands of transgenic mice leads to a reactive stroma during early development. Am. J. Pathol. 153, 457-467. doi: 10.1016/s0002-9440(10)655897

Tong, D., Liu, Q., Wang, L. A., Xie, Q., Pang, J., Huang, Y., et al. (2018). The roles of the COX2/PGE2/EP axis in therapeutic resistance. Cancer Metastasis Rev. 37, 355-368. doi: 10.1007/s10555-018-9752-y

Tran, Q., Lee, H., Park, J., Kim, S.-H., and Park, J. (2016). Targeting cancer metabolism-revisiting the Warburg effects. Toxicol. Res. 32, 177-193.

Trédan, O., Galmarini, C. M., Patel, K., and Tannock, I. F. (2007). Drug resistance and the solid tumor microenvironment. J. Natl. Cancer Inst. 99, 1441-1454.

Truffi, M., Sorrentino, L., and Corsi, F. (2020). "Fibroblasts in the tumor microenvironment," in Tumor Microenvironment: Non-Hematopoietic Cells, ed. A. Birbrair (Cham: Springer International Publishing), 15-29.

Tsai, M. J., Chang, W. A., Huang, M. S., and Kuo, P. L. (2014). Tumor microenvironment: a new treatment target for cancer. ISRN Biochem. 2014:351959. doi: 10.1155/2014/351959

Tulotta, C., and Ottewell, P. (2018). The role of IL-1B in breast cancer bone metastasis. Endocr. Relat. Cancer 25, R421-R434. doi: 10.1530/erc-17-0309

Umezawa, K., Kojima, I., Simizu, S., Lin, Y., Fukatsu, H., Koide, N., et al. (2018). Therapeutic activity of plant-derived alkaloid conophylline on metabolic syndrome and neurodegenerative disease models. Hum. Cell 31, 95-101. doi: 10.1007/s13577-017-0196-4

Upagupta, C., Shimbori, C., Alsilmi, R., and Kolb, M. (2018). Matrix abnormalities in pulmonary fibrosis. Eur. Respir Rev. 27:180033. doi: 10.1183/16000617.00332018

Valencia, A. M., and Kadoch, C. (2019). Chromatin regulatory mechanisms and therapeutic opportunities in cancer. Nat. Cell Biol. 21, 152-161. doi: 10.1038/ s41556-018-0258-1

Vaquero, J., Lobe, C., Tahraoui, S., Clapéron, A., Mergey, M., Merabtene, F., et al. (2018). The IGF2/IR/IGF1R pathway in tumor cells and myofibroblasts mediates resistance to egfr inhibition in cholangiocarcinoma. Clin. Cancer Res. 24, 4282-4296. doi: 10.1158/1078-0432.Ccr-17-3725

Vaupel, P. (2004). Tumor microenvironmental physiology and its implications for radiation oncology. Semin. Radiat. Oncol. 14, 198-206.

Vlachogiannis, G., Hedayat, S., Vatsiou, A., Jamin, Y., Fernández-Mateos, J., Khan, K., et al. (2018). Patient-derived organoids model treatment response of metastatic gastrointestinal cancers. Science 359, 920-926. doi: 10.1126/science. aao 2774

Walker, C., Mojares, E., and del Río Hernández, A. (2018). Role of extracellular matrix in development and cancer progression. Int. J. Mol. Sci. 19:3028.

Wang, L., Zhang, F., Cui, J. Y., Chen, L., Chen, Y. T., and Liu, B. W. (2018). CAFs enhance paclitaxel resistance by inducing EMT through the IL-6/JAK2/STAT3 pathway. Oncol. Rep. 39, 2081-2090. doi: 10.3892/or.2018.6311

Wang, X., Luo, G., Zhang, K., Cao, J., Huang, C., Jiang, T., et al. (2018). Hypoxic tumor-derived exosomal miR-301a mediates M2 macrophage polarization via PTEN/PI3K $\gamma$ to promote pancreatic cancer metastasis. Cancer Res. 78, 45864598. doi: 10.1158/0008-5472.Can-17-3841

Wang, M., Qiu, R., Yu, S., Xu, X., Li, G., Gu, R., et al. (2019). Paclitaxel-resistant gastric cancer MGC-803 cells promote epithelial-to-mesenchymal transition 
and chemoresistance in paclitaxel-sensitive cells via exosomal delivery of miR155-5p. Int. J. Oncol. 54, 326-338.

Wang, W., Kryczek, I., Dostál, L., Lin, H., Tan, L., Zhao, L., et al. (2016). Effector T Cells abrogate stroma-mediated chemoresistance in ovarian cancer. Cell 165, 1092-1105. doi: 10.1016/j.cell.2016.04.009

Wang, W. L., Chang, W. L., Yang, H. B., Chang, I. W., Lee, C. T., Chang, C. Y., et al. (2015). Quantification of tumor infiltrating Foxp3+ regulatory T cells enables the identification of high-risk patients for developing synchronous cancers over upper aerodigestive tract. Oral. Oncol. 51, 698-703. doi: 10.1016/j.oraloncology. 2015.04.015

Wang, Y., Fang, Z., Hong, M., Yang, D., and Xie, W. (2020). Long-noncoding RNAs (lncRNAs) in drug metabolism and disposition, implications in cancer chemoresistance. Acta Pharmaceut. Sin. B 10, 105-112. doi: 10.1016/j.apsb.2019.09. 011

Warfel, N. A., and El-Deiry, W. S. (2014). HIF-1 signaling in drug resistance to chemotherapy. Curr. Med. Chem. 21, 3021-3028. doi: 10.2174/0929867321666140414101056

Watnick, R. S. (2012). The role of the tumor microenvironment in regulating angiogenesis. Cold Spring Harbor Perspect. Med. 2:a006676.

Wei, S. C., Duffy, C. R., and Allison, J. P. (2018). Fundamental mechanisms of immune checkpoint blockade therapy. Cancer Discov. 8, 1069-1086. doi: 10. 1158/2159-8290.Cd-18-0367

Weigelt, B., Lo, A. T., Park, C. C., Gray, J. W., and Bissell, M. J. (2010). HER2 signaling pathway activation and response of breast cancer cells to HER2targeting agents is dependent strongly on the 3D microenvironment. Breast Cancer Res. Treatm. 122, 35-43. doi: 10.1007/s10549-009-0502-2

Weinberg, F., Ramnath, N., and Nagrath, D. (2019). Reactive oxygen species in the tumor microenvironment: an overview. Cancers 11:1191. doi: 10.3390/ cancers 11081191

Weis, S. M., and Cheresh, D. A. (2011). Tumor angiogenesis: molecular pathways and therapeutic targets. Nat. Med. 17, 1359-1370.

Wight, T. N., Kang, I., Evanko, S. P., Harten, I. A., Chang, M. Y., Pearce, O. M. T., et al. (2020). Versican-A critical extracellular matrix regulator of immunity and inflammation. Front. Immunol. 11:512. doi: 10.3389/fimmu.20 20.00512

Wolchok, J. D., Kluger, H., Callahan, M. K., Postow, M. A., Rizvi, N. A., Lesokhin, A. M., et al. (2013). Nivolumab plus ipilimumab in advanced melanoma. N. Engl. J. Med. 369, 122-133. doi: 10.1056/NEJMoa1302369

Wu, A. T., Srivastava, P., Yadav, V. K., Tzeng, D. T., Iamsaard, S., Su, C.Y., et al. (2020). Ovatodiolide, isolated from Anisomeles indica, suppresses bladder carcinogenesis through suppression of mTOR/ $\beta$-catenin/CDK6 and exosomal miR-21 derived from M2 tumor-associated macrophages. Toxicol. Appl. Pharmacol. 401:115109.

Wu, D., Zhuo, L., and Wang, X. (2017). Metabolic reprogramming of carcinomaassociated fibroblasts and its impact on metabolic heterogeneity of tumors. Semin. Cell Dev. Biol. 64, 125-131. doi: 10.1016/j.semcdb.2016.11.003

Wu, J., Li, G., Li, L., Li, D., Dong, Z., and Jiang, P. (2021). Asparagine enhances LCK signalling to potentiate CD8+ T-cell activation and anti-tumour responses. Nat. Cell Biol. 23, 75-86. doi: 10.1038/s41556-020-00615-4

Xia, Y., Jiang, L., and Zhong, T. (2018). The role of HIF-1 $\alpha$ in chemo/radioresistant tumors. OncoTargets Ther. 11, 3003-3011. doi: 10.2147/OTT. S158206

Xie, N., Zhang, L., Gao, W., Huang, C., Huber, P. E., Zhou, X., et al. (2020). NAD(+) metabolism: pathophysiologic mechanisms and therapeutic potential. Signal Transduct. Target. Ther. 5:227. doi: 10.1038/s41392-020-00311-7

Xu, M., Liu, M., Du, X., Li, S., Li, H., Li, X., et al. (2015). Intratumoral delivery of IL-21 overcomes Anti-Her2/Neu resistance through shifting tumor-associated macrophages from M2 to M1 Phenotype. J. Immunol. 194, 4997-5006. doi: 10.4049/jimmunol.1402603

Yamada, K., Maishi, N., Akiyama, K., Towfik Alam, M., Ohga, N., Kawamoto, T., et al. (2015). CXCL12-CXCR7 axis is important for tumor endothelial cell angiogenic property. Int. J. Cancer 137, 2825-2836.

Yamashita, M., Ogawa, T., Zhang, X., Hanamura, N., Kashikura, Y., Takamura, M., et al. (2012). Role of stromal myofibroblasts in invasive breast cancer: stromal expression of alpha-smooth muscle actin correlates with worse clinical outcome. Breast Cancer 19, 170-176. doi: 10.1007/s12282-010-0234-5

Yang, E., Wang, X., Gong, Z., Yu, M., Wu, H., and Zhang, D. (2020). Exosome-mediated metabolic reprogramming: the emerging role in tumor microenvironment remodeling and its influence on cancer progression. Signal Transduct. Target. Ther. 5:242. doi: 10.1038/s41392-020-00359-5

Yang, G., Shi, R., and Zhang, Q. (2020). Hypoxia and oxygen-sensing signaling in gene regulation and cancer progression. Int. J. Mol. Sci. 21:8162. doi: 10.3390/ ijms 21218162

Yang, Y., Neo, S. Y., Chen, Z., Cui, W., Chen, Y., Guo, M., et al. (2020). Thioredoxin activity confers resistance against oxidative stress in tumor-infiltrating NK cells. J. Clin. Invest. 130, 5508-5522. doi: 10.1172/jci137585

Yang, J., Lu, Y., Lin, Y. Y., Zheng, Z. Y., Fang, J. H., He, S., et al. (2016). Vascular mimicry formation is promoted by paracrine TGF- $\beta$ and SDF1 of cancer-associated fibroblasts and inhibited by miR-101 in hepatocellular carcinoma. Cancer Lett. 383, 18-27. doi: 10.1016/j.canlet.2016.0 9.012

Yarnold, J., and Brotons, M. C. (2010). Pathogenetic mechanisms in radiation fibrosis. Radiother. Oncol. 97, 149-161. doi: 10.1016/j.radonc.20 10.09.002

Yin, W. M., Li, Y. W., Gu, Y. Q., and Luo, M. (2020). Nanoengineered targeting strategy for cancer immunotherapy. Acta Pharmacol. Sin. 41, 902-910. doi: 10.1038/s41401-020-0417-3

Yin, Y., Yao, S., Hu, Y., Feng, Y., Li, M., Bian, Z., et al. (2017). The immunemicroenvironment confers chemoresistance of colorectal cancer through macrophage-derived IL6. Clin. Cancer Res. 23, 7375-7387. doi: 10.1158/10780432.Ccr-17-1283

Yonenaga, Y., Mori, A., Onodera, H., Yasuda, S., Oe, H., Fujimoto, A., et al. (2005). Absence of smooth muscle actin-positive pericyte coverage of tumor vessels correlates with hematogenous metastasis and prognosis of colorectal cancer patients. Oncology 69, 159-166.

Yoshizaki, T., Kondo, S., Wakisaka, N., Murono, S., Endo, K., Sugimoto, H., et al. (2013). Pathogenic role of Epstein-Barr virus latent membrane protein1 in the development of nasopharyngeal carcinoma. Cancer Lett. 337, 1-7. doi: 10.1016/j.canlet.2013.05.018

You, Y., Shan, Y., Chen, J., Yue, H., You, B., Shi, S., et al. (2015). Matrix metalloproteinase 13-containing exosomes promote nasopharyngeal carcinoma metastasis. Cancer Sci. 106, 1669-1677. doi: 10.1111/cas.12818

Yu, X., Lao, Y., Teng, X. L., Li, S., Zhou, Y., Wang, F., et al. (2018). SENP3 maintains the stability and function of regulatory T cells via BACH2 deSUMOylation. Nat. Commun. 9:3157. doi: 10.1038/s41467-018-05676-6

Yuan, M.-M., Xu, Y.-Y., Chen, L., Li, X.-Y., Qin, J., and Shen, Y. (2015). TLR3 expression correlates with apoptosis, proliferation and angiogenesis in hepatocellular carcinoma and predicts prognosis. BMC Cancer 15:245. doi: 10.1186/s12885-015-1262-5

Zaidi, M., Fu, F., Cojocari, D., McKee, T. D., and Wouters, B. G. (2019). Quantitative visualization of hypoxia and proliferation gradients within histological tissue sections. Front. Bioeng. Biotechnol. 7:397. doi: 10.3389/fbioe. 2019.00397

Zeng, Z., Li, Y., Pan, Y., Lan, X., Song, F., Sun, J., et al. (2018). Cancer-derived exosomal miR-25-3p promotes pre-metastatic niche formation by inducing vascular permeability and angiogenesis. Nat. Commun. 9:5395. doi: 10.1038/ s41467-018-07810-w

Zhang, B., Fu, D., Xu, Q., Cong, X., Wu, C., Zhong, X., et al. (2018). The senescenceassociated secretory phenotype is potentiated by feedforward regulatory mechanisms involving Zscan4 and TAK1. Nat. Commun. 9:1723. doi: 10.1038/ s41467-018-04010-4

Zhang, D., Li, L., Jiang, H., Li, Q., Wang-Gillam, A., Yu, J., et al. (2018). Tumor-stroma IL1 $\beta$-IRAK4 feedforward circuitry drives tumor fibrosis, chemoresistance, and poor prognosis in pancreatic cancer. Cancer Res. 78, 1700-1712. doi: 10.1158/0008-5472.Can-17-1366

Zhang, H., Ozaki, I., Mizuta, T., Matsuhashi, S., Yoshimura, T., Hisatomi, A., et al. (2002). $\beta 1$-integrin protects hepatoma cells from chemotherapy induced apoptosis via a mitogen-activated protein kinase dependent pathway. Cancer 95, 896-906. doi: $10.1002 / \mathrm{cncr} .10751$

Zhang, J., Pavlova, N. N., and Thompson, C. B. (2017). Cancer cell metabolism: the essential role of the nonessential amino acid, glutamine. Embo J. 36, 1302-1315. doi: 10.15252/embj.201696151

Zhang, Q., Bing, Z., Tian, J., Wang, X., Liu, R., Li, Y., et al. (2019). Integrating radiosensitive genes improves prediction of radiosensitivity or radioresistance in patients with oesophageal cancer. Oncol. Lett. 17, 5377-5388. doi: 10.3892/ ol.2019.10240 
Wu et al.

TME in Adaptive Resistance

Chang, Z., Yu, X., Wang, Z., Wu, P., and Huang, J. (2015). Anthracyclines potentiate antitumor immunity: a new opportunity for chemoimmunotherapy. Cancer Lett. 369, 331-335. do: 10.1016/j.canlet.2015.10.002

Zhao, J. (2016). Cancer stem cells and chemoresistance: the smartest survives the raid. Pharmacol. Then. 160, 145-158. do: 10.1016/j.pharmthera.2016.02.008

Zhao, J., Du, F., Duo, Y., Shen, G., Zheng, F., and Xu, B. (2015). The emerging role of hypoxia-inducible factor-2 involved in chemo/radioresistance in solid tumors. Cancer Treat. Rev. 41, 623-633. doa: 10.1016/j.ctrv.2015.05.004

Zhao, P., Wang, Y., Kang, X., Wu, A., Yin, W., Tang, Y., et al. (2018). Dualtargeting biomimetic delivery for anti-glioma activity via remodeling the tumor microenvironment and directing macrophage-mediated immunotherapy. Chem. Sci. 9, 2674-2689.

Zhao, Q., Tan, B. B., Li, Y., Fan, L. Q., Yang, P. G., and Tin, Y. (2016). Enhancement of drug sensitivity by knockdown of HIF-1 $\alpha$ in gastric carcinoma cells. Oncol. Res. 23, 129-136. do: 10.3727/096504015x14500513118029

Chen, Z., Tang, W., Wang, M., Zhou, S., Wang, H., Wu, Z., et al. (2017). Protein nanocage mediated fibroblast-activation protein targeted photoimmunotherapy to enhance cytotoxic t cell infiltration and tumor control. Nano Lett. 17, 862-869. do: 10.1021/acs.nanolett.6b04150

Zheng, H., Zhao, W., Yan, C., Watson, C. C., Massengill, M., Xie, M., et al. (2016). HDAC inhibitors enhance T-Cell chemokine expression and augment response to PD-1 immunotherapy in lung adenocarcinoma. Chin. Cancer Res. 22, 4119-4132. doa: 10.1158/1078-0432.Ccr-15-2584

Zheng, P., Chen, L., Yuan, X., Luo, Q., Lu, Y., Xe, G., et al. (2017). Exosomal transfer of tumor-associated macrophage-derived miR-21 confers cisplatin resistance in gastric cancer cells. J. Exp. Chin. Cancer Res. 36:53.

Zhong, A., Cheng, C. S., Kari, J., Lu, R., and Gus, L. (2020). Clinical significance of glucose to lymphocyte ratio (GLR) as a prognostic marker for patients with pancreatic cancer. Front. Oncol. 10:520330. do: 10.3389/fonc.2020.520330

Zhong, Z., and Virshup, D. M. (2020). Wit signaling and drug resistance in cancer. Mol. Pharmacol. 97, 72-89. do: 10.1124/mol.119.117978

Chou, Z., Piao, Y., Hoo, L., Wang, G., Zhou, Z., and Shen, Y. (2019). Acidityresponsive shell-sheddable camptothecin-based nanofibers for carrier-free cancer drug delivery. Nanoscale 11, 15907-15916.

Zingy, D., Arenas-Ramirez, N., Shin, D., Rosalia, R. A., Antunes, A. T., Haeusel, J., et al. (2017). The histone methyltransferase Ezh2 controls mechanisms of adaptive resistance to tumor immunotherapy. Cell Rep. 20, 854-867. doa: 10. 1016/j.celrep.2017.07.007

Conflict of Interest: The authors declare that the research was conducted in the absence of any commercial or financial relationships that could be construed as a potential conflict of interest.

Copyright (c) 2021 Wu, Gao, Si, Nice, Chang, Lin and Xe. This is an open-access article distributed under the terms of the Creative Commons Attribution License (CC BY). The use, distribution or reproduction in other forums is permitted, provided the original authors) and the copyright owners) are credited and that the original publication in this journal is cited, in accordance with accepted academic practice. No use, distribution or reproduction is permitted which does not comply with these terms.

Frontiers in Cell and Developmental Biology | www.frontiersin.org

23

March 2021 | Volume 9 | Article 641469 